\title{
NMR Spectral Characteristics of Ultrahigh Pressure High Temperature Impact Glasses of the Giant Kara Crater (Pay-Khoy, Russia)
}

\author{
Vladimir Lyutoev ${ }^{1, *(D)}$, Tatyana Shumilova ${ }^{1}$, Anton Mazur ${ }^{2}$ and Peter Tolstoy ${ }^{3}$ \\ 1 Institute of Geology, FRC Komi Science Center, Ural Branch, Russian Academy of Sciences, \\ 167982 Syktyvkar, Russia; shumilova@geo.komisc.ru \\ 2 Center for Magnetic Resonance, Research Park, St. Petersburg State University, 198504 St. Petersburg, Russia; \\ a.mazur@spbu.ru \\ 3 Institute of Chemistry, St. Petersburg State University, 198504 St. Petersburg, Russia; peter.tolstoy@spbu.ru \\ * Correspondence: vlutoev@geo.komisc.ru
}

check for

updates

Citation: Lyutoev, V.; Shumilova, T.; Mazur, A.; Tolstoy, P. NMR Spectral Characteristics of Ultrahigh Pressure High Temperature Impact Glasses of the Giant Kara Crater (Pay-Khoy, Russia). Minerals 2021, 11, 1418. https://doi.org/10.3390/min11121418

Academic Editors:

Luis Sánchez-Muñoz and

Pierre Florian

Received: 15 November 2021

Accepted: 13 December 2021

Published: 15 December 2021

Publisher's Note: MDPI stays neutral with regard to jurisdictional claims in published maps and institutional affiliations.

Copyright: (c) 2021 by the authors. Licensee MDPI, Basel, Switzerland. This article is an open access article distributed under the terms and conditions of the Creative Commons Attribution (CC BY) license (https:/ / creativecommons.org/licenses/by/ $4.0 /)$.

\begin{abstract}
In this study, we carried out the analysis of the impact melt vein glasses from the Kara impact crater (Russia) in comparison to low-pressure impact melt glasses (tektites) of the Zhamanshin crater (Kazakhstan). ${ }^{27} \mathrm{Al},{ }^{23} \mathrm{Na}$, and ${ }^{29} \mathrm{Si}$ MAS NMR spectra of the samples of these glasses were analyzed. The samples of the natural glass contained inclusions of crystalline phases, paramagnetic elements that greatly complicate and distort the NMR signals from the glass phase itself. Taking into account the Mossbauer distribution of Fe in these glasses, the analysis of the spectra of MAS NMR of glass network-former $(\mathrm{Si}, \mathrm{Al})$ and potential network-modifiers $(\mathrm{Na})$ of nuclei leads to the conclusion that the Kara impact melt vein glasses are characterized by complete polymerization of $(\mathrm{Si}, \mathrm{Al}) \mathrm{O}_{4}$ tetrahedral structural units. The NMR features of the glasses are consistent with the vein hypothesis of their formation under conditions of high pressures and temperatures resulting in their fluidity, relatively slow solidification with partial melt differentiation, polymerization, and precipitation of mineral phases as the impact melt cools. The 70 Ma stability of the Kara impact vein glass can be explained by the stabilization of the glass network with primary fine-dispersed pyroxene and coesite precipitates and by the high polymerization level of the impact glass.
\end{abstract}

Keywords: ultrahigh-pressure high-temperature impact glasses; Kara impact crater; MAS NMR; alumosilicate glass framework

\section{Introduction}

The state of matter under extreme conditions and the structure and properties of disordered materials formed under strong compressions are actively studied both theoretically and experimentally [1-8]. In this sense, ultrahigh-pressure (UHP) glasses are particularly interesting both from a fundamental point of view and due to their possible use as materials $[9,10]$ with potential high-tech applications in photonics, laser technologies, including optical lasers, optical wave amplifiers, and others [11]. Synthesized materials generally have microscopic dimensions and are produced at pressures of up to $100 \mathrm{GPa}$ and higher, but at room temperature, which is limited by the technical capabilities of the experimental equipment-diamond anvils [3-5,7,8,10]. In fact, mainly diaplectic glasses are studied, which are solid substances amorphized under high pressure, not undergoing the first-order phase transition (i.e., without changing the aggregate state of the substance). For example, the impact influence on quartz results in the formation of diaplectic quartz glass, which is characterized by a higher density and a larger average Si-O-Si bond angle, but the formation of the octahedral coordination of silicon in the glass network is kinetically difficult.

The synthesis of materials under the influence of both high pressures and high temperatures with the formation of UHP melts and their solidification products is interesting 
both in terms of the fundamental state of the substance and in anticipation of the specific properties of materials [12]. From this point of view, the discovered natural ultrahighpressure high-temperature (UHPHT) melt impact glasses with monocrystalline coesite [13] formed at pressures of more than $60 \mathrm{GPa}$ and temperature of about $2800 \mathrm{~K}$ in the giant Kara impact crater (Pay-Khoy, Russia) [14] are of great interest. Using ${ }^{57} \mathrm{Fe}$ Mössbauer spectroscopy, a small portion of ferrous iron ions in 8 -fold coordination $(4 \%)$, similar to the structural positions of ions in garnets, was revealed in Kara glasses [14,15]. Since mineral segregations of crystalline garnet in the glass were not found, an assumption about the densification of the glass framework due to the solidification of the impact melt under high pressure was made.

In the Raman spectra of the Kara UHPHT glasses [16], in addition to vibrational bands of the $\mathrm{SiO}_{4}$-framework in the region of $400-800 \mathrm{~cm}^{-1}$, the stretching band of $\mathrm{Si}-\mathrm{OH}$ groups (960-970 $\mathrm{cm}^{-1}$ ) and the bands related to the vibrations of $\mathrm{SiO}_{4}$ groups with 1, 2 and 4 non-bridging oxygen atoms (so-called $\mathrm{Q}^{3}, \mathrm{Q}^{2}$ and $\mathrm{Q}^{0}$ units) were identified in the range of $800-1200 \mathrm{~cm}^{-1}$. Interestingly, in the Raman spectra of aluminosilicate and pure silicate fragments of the Kara glass, the band shapes in the range of $800-1200 \mathrm{~cm}^{-1}$ were almost identical, with a small predominance of $Q^{2}$ and $Q^{3}$ units over $Q^{0}$ in the former and their uniform distribution in the latter. It was concluded that in comparison with other impact glasses, the Kara glass is characterized by a significant heterogeneity of the degree of polymerization of silicon-oxygen tetrahedra. The discovery of a high concentration of non-bridging oxygen atoms was highly unexpected based on the results [17] used for the interpretation of Raman spectra. In addition, electron microscopic images presented in $[13,16]$ showed the presence of widespread pyroxene $\left(Q^{2}\right)$ microcrystallites in the glass matrix. These observations call for further investigation of the polymerization of the UHPHT impact Kara glasses.

Among modern methods for studying glass structures, one of the most informative techniques is multinuclear NMR spectroscopy $[17,18]$. In this paper, the results of studies of the nearest environment of general elements of the aluminosilicate and silicate framework of natural UHP impact glasses of the Kara crater in comparison to natural impact melt glasses of low-pressure (LP) condensation-tektites of the Zhamanshin crater (Kazakhstan) by ${ }^{29} \mathrm{Si},{ }^{27} \mathrm{Al}$ and ${ }^{23} \mathrm{Na}$ MAS NMR are presented for the first time.

\section{Materials and Methods}

UHPHT melt impact glasses were sampled in 2015 and 2017 from impactites of the southern sector of the Kara crater from vein bodies cutting suevite massif (Figure 1) at the Kara River (Pay-Khoy, Russia) and these are samples KP15-12-115 and KP15-12-118. A preliminary analysis of the structural state of these glasses was carried out using a set of standard mineralogical research methods $[13,14,16]$. The main feature distinguishing UHPHT melts from clast type glasses and massive melt impactites was found to be the multilevel differentiation of impact melt, including liquation of silicate and aluminosilicate melts and partial silica melt crystallization to $\mathrm{UHP} \mathrm{SiO}_{2}$ variety-monocrystalline coesite [13,14].

The objects of comparison were zhamanshinites (irgizites)—impact glasses related to trans-crater tektites of the Zhamanshin meteorite crater (Kazakhstan)-ZH1, and ZH2 samples. Tektites are hardened drops of impact melt ejected into the atmosphere during the formation of a crater, i.e., condensed at atmospheric pressure. They are related to LP glasses [19-21]. A number of petrographic and chemical features indicate that tektites resulted from high-temperature melting (more than $2000 \mathrm{~K}$ ) with fast melt cooling. 


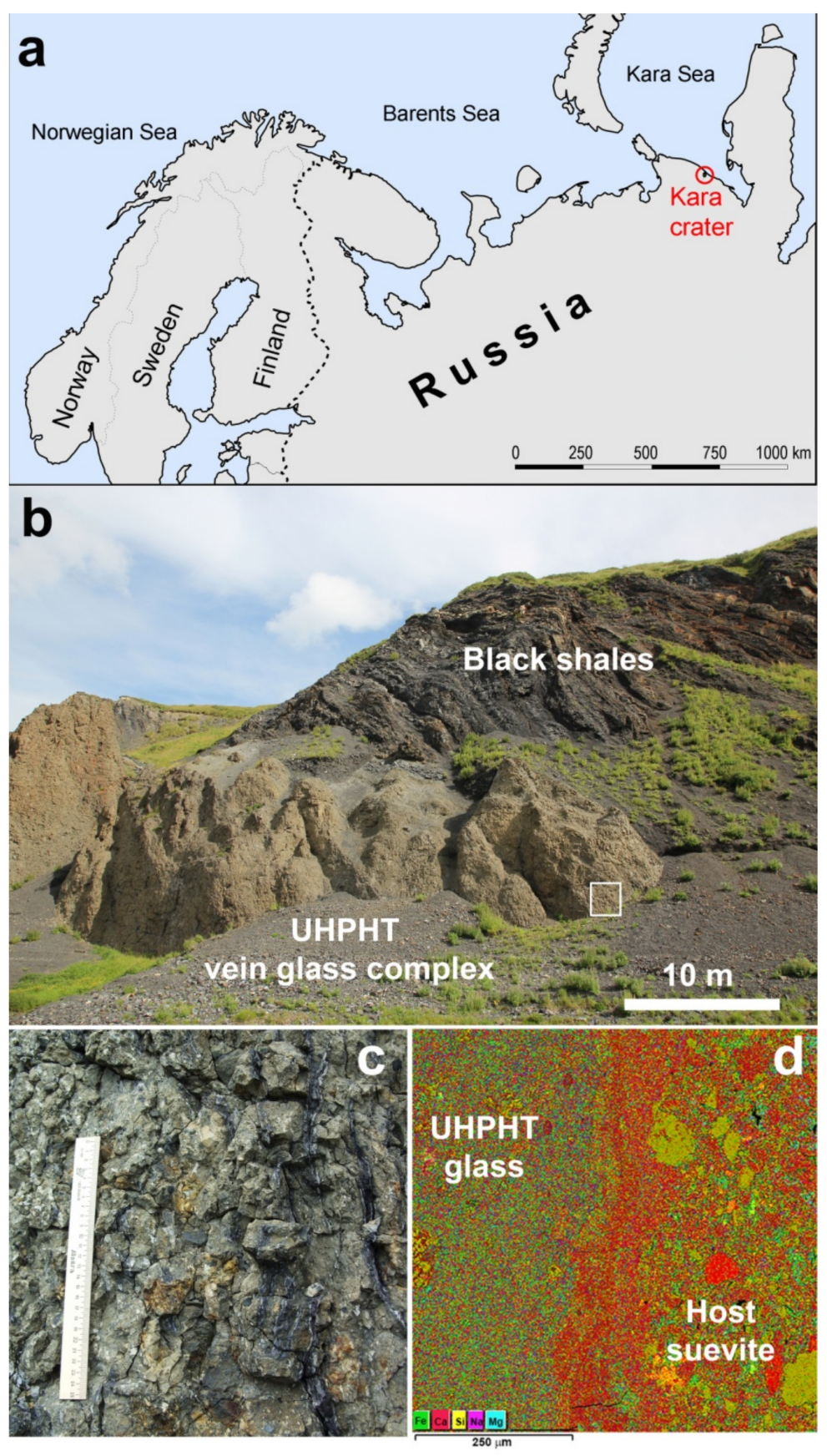

Figure 1. The Kara UHPHT vein glasses: (a) — geographic position of the Kara crater; (b)—sampled point within the suevite complex (marked by a white square), origin outcrop at the right bank of the Kara river (Pay-Khoy); (c)—vein glasses position within the host suevite; (d)—an electron microprobe multicomponent elemental map of the UHPHT glass (left side) with a quenched zone (central vertical zone) in the host suevite.

The monomineral fractions of all the studied samples were separated under a binocular microscope to avoid contamination by the host suevitic matter. Preliminarily, the selected samples of the UHPHT Kara glasses and zhamanshinites were analyzed at Center of Collective Use "Geonauka" (Syktyvkar, IG FRC Komi SC UB RAS) using X-ray powder diffraction (XRD-6000, Shimadzu, Japan), ${ }^{57} \mathrm{Fe}$ Mössbauer (MS-1104Em, Rostov State University, Russia), infrared (FTIR FT-02, Lumex, Russia) and Raman (LabRam HR 800, Horiba Jobin Yvon, France) spectroscopy, scanning electron microscopy, and microprobe analysis (TESCAN VEGA3 with Oxford EDS X-Max, Brno, Czech Republic). The results of 
their study by these methods are published elsewhere $[13,15,16]$. In this paper, they are supplemented by additional microprobe analyses.

The high-resolution ${ }^{29} \mathrm{Si},{ }^{27} \mathrm{Al}$ and ${ }^{23} \mathrm{Na}$ MAS NMR studies of the impact glass samples were carried out at the Center for Magnetic Resonance (SPbU Research Park) using Bruker Avance III 400 WB spectrometer (9.4 T; operating frequencies 105.87, 104.29, and 79.51 MHz for ${ }^{23} \mathrm{Na},{ }^{27} \mathrm{Al}$, and ${ }^{29} \mathrm{Si}$ nuclei, respectively). The KP15-12-115 and KP15-12-118 samples were placed in a rotor with an external diameter of $4 \mathrm{~mm}$ and spun at $14 \mathrm{kHz}$ at the magic angle relative to the direction of the magnetic field for the acquisition of ${ }^{23} \mathrm{Na}$, ${ }^{27} \mathrm{Al}$, and ${ }^{29} \mathrm{Si}$ MAS NMR spectra. The low amount of the sample required the usage of $4 \mathrm{~mm}$ rotors with reduced inner volume so that the whole sample material stayed in the detected volume of the receiver coil. The amount of material for the ZH1 and ZH2 samples was enough to fill a standard rotor with an external diameter of $3.2 \mathrm{~mm}$. The resulting samples were spun at $17.5 \mathrm{kHz}$ (for ${ }^{27} \mathrm{Al}$ and ${ }^{23} \mathrm{Na} \mathrm{NMR}$ spectra) and $12.5 \mathrm{kHz}$ (for ${ }^{29} \mathrm{Si}$ NMR spectra; lower spinning rate allowed for better detection of spinning sidebands, which were used for phase and baseline correction). In all cases, a single-pulse excitation sequence was used (direct excitation technique). The relaxation delay for ${ }^{23} \mathrm{Na},{ }^{27} \mathrm{Al}$, and ${ }^{29}$ Si nuclei was $2.5,1$, and $5 \mathrm{~s}$, the excitation pulse durations were $2.5 \mu \mathrm{s}, 1.6 \mu \mathrm{s}$, and $4 \mu \mathrm{s}$, and the number of scans were 2048,8192 , and 4098 , respectively. The relaxation delay for ${ }^{29} \mathrm{Si}$ NMR spectra was optimized, i.e., the preliminary measurements confirmed that $5 \mathrm{~s}$ was sufficient for the consistent registration of ${ }^{29} \mathrm{Si}$ NMR spectra. We attribute the short relaxation time to the presence of paramagnetic impurities. Aqueous solutions of $\mathrm{NaCl}$, $\mathrm{AlCl}$, and tetramethylsilane (TMS) were used as external references for ${ }^{23} \mathrm{Na},{ }^{27} \mathrm{Al}$, and ${ }^{29} \mathrm{Si}$ nuclei, respectively.

DMFit program (release \#20200306) of the NMR@CEMHTI web page was used for fitting the spectra [22]. As a measure of the errors in determining the fit parameters, triple values of the standard deviation obtained from 30-50 cycles of the DMFit subroutine of the Monte Carlo error model were taken.

\section{Results}

\subsection{Samples Characterization}

The data on the averaged microprobe chemical analyses of the studied samples are presented in Table 1. The samples of the UHPHT melt vein glasses from the Kara crater are characterized by similar chemical composition. Their elemental rations correspond to mainly anorthoclase composition. The atomic fraction of iron $(\mathrm{Fe} /(\mathrm{Fe}+\mathrm{Si}+\mathrm{Al}))$ in the aluminosilicate framework of these glass samples is $0.06-0.07$, while in the tektite glass ZH1 it is noticeably lower, and in $\mathrm{ZH} 2$ it is almost halved. Additionally, the tektites differ from the UHPHT Kara glasses by significantly lower ratios of $\mathrm{Al} /(\mathrm{Si}+\mathrm{Al})$ and $\mathrm{Na} /(\mathrm{Na}+\mathrm{K})$. It is important to note that the compositions similar to those of ZH1 and ZH2 samples for irgizites of the Zhamanshin meteorite crater were obtained earlier by other authors [19-22].

According to Raman and IR spectroscopy, XRD, and microprobe analysis, rare segregations of pure $\mathrm{SiO}_{2}$ glass, clinopyroxene, coesite, smectite, and rare micrograins of iron sulfides in UHPHT glasses have been obtained by previous works $[13,14,16]$. The presence of inclusions of iron-containing minerals (pyroxene and sulfides) in the Kara glasses indicates that the atomic fraction of iron $(\mathrm{Fe} /(\mathrm{Fe}+\mathrm{Si}+\mathrm{Al}))$ directly in the aluminosilicate glass framework is slightly lower than the average value of $0.06-0.07$. There are also rare relict fragments of the target rocks in the Kara glasses such as inclusions of quartz, feldspar, calcite, and mica minerals, that cannot be completely mechanically removed from the analyzed glass samples. In contrast, the LP tektites are predominantly homogeneous but contain few segregations of pure $\mathrm{SiO}_{2}$ glass. 
Table 1. Major element contents of the UHPHT and LP impact glasses, average microprobe data, wt.\%.

\begin{tabular}{ccccc}
\hline Component & KP15-12-115 & KP15-12-118 & ZH1 & ZH2 \\
\hline $\mathrm{SiO}_{2}$ & 56.15 & 57.22 & 74.29 & 71.25 \\
$\mathrm{TiO}_{2}$ & 0.83 & 0.95 & 0.81 & 0.53 \\
$\mathrm{Al}_{2} \mathrm{O}_{3}$ & 14.47 & 15.94 & 9.89 & 10.30 \\
$\mathrm{FeO}$ & 5.50 & 6.48 & 5.66 & 3.58 \\
$\mathrm{MnO}$ & n.d. & n.d. & 0.01 & n.d. \\
$\mathrm{NiO}$ & n.d. & n.d. & 0.06 & 1.96 \\
$\mathrm{CaO}$ & 2.99 & 3.26 & 2.39 & 0.87 \\
$\mathrm{MgO}$ & 4.39 & 5.45 & 2.91 & 2.85 \\
$\mathrm{~K}{ }_{2} \mathrm{O}$ & 1.93 & 1.86 & 2.16 & 1.66 \\
$\mathrm{Na}{ }_{2} \mathrm{O}$ & 2.77 & 2.16 & 1.02 & 93.00 \\
$\mathrm{Sum}$ & 89.02 & 93.32 & 99.2 & 0.15 \\
$\mathrm{Al} /(\mathrm{Si}+\mathrm{Al})^{1}$ & 0.23 & 0.25 & 0.14 & 0.47 \\
$\mathrm{Na} /(\mathrm{Na}+\mathrm{K})^{1}$ & 0.69 & 0.64 & 0.47 & 0.03 \\
$\mathrm{Fe} /(\mathrm{Fe}+\mathrm{Si}+\mathrm{Al})^{1}$ & 0.06 & 0.07 & 0.05 & \\
\hline
\end{tabular}

1 Atomic ratios.

In Table 1, the total iron content is attributed to the ferrous oxide form. However, according to ${ }^{57} \mathrm{Fe}$ Mössbauer spectroscopy, approximately $1 / 3$ of the iron in these samples is represented by $\mathrm{Fe}^{3+}$ ions: the module $\mathrm{Fe}^{3+} /\left(\mathrm{Fe}^{2+}+\mathrm{Fe}^{3+}\right)$ is 0.36 for the UHPHT glass KP15-12-115 [14] and 0.3 for the analyzed zhamanshinite [15]. This degree of iron oxidation is relatively high compared to some of the previously studied samples: 0.12 [14] for the impact glass of the Ries crater and 0.18 [15,23] for the volcanic glass of basalt pumice lava of caldera of the Mauna Loa volcano in Hawaii. The degree of iron oxidation in technogenic glass (tengesite), which had very long contact with the atmosphere in the molten state, is much higher, with its modulus $\mathrm{Fe}^{3+} /\left(\mathrm{Fe}^{2+}+\mathrm{Fe}^{3+}\right)$ reaching values of $0.5-0.6$ [15]. The iron dissolved in the tektite LP glass has only the octahedral coordination of the nearest oxygen environment, but the Kara UHPHT glass has about 9 and 4 at.\% of iron with 4-5-fold and 8 -fold oxygen coordination, respectively.

\section{2. ${ }^{27}$ Al MAS NMR}

Figure 2 shows the ${ }^{27} \mathrm{Al}$ MAS NMR spectra of KP15-12-115, KP15-12-118, ZH1 and $\mathrm{ZH} 2$ samples. Each spectrum is characterized by an intensive central band and a set of spinning sidebands (ssb) shifted from the central band by the MAS spinning frequency ( $14 \mathrm{kHz}$ and $17.5 \mathrm{kHz}$ for samples of Kara glass and zhamanshinites, respectively). The extended ssb structure is a characteristic of quadrupole nuclei, such as ${ }^{27} \mathrm{Al}$ (nuclear spin $\mathrm{I}=5 / 2$ ), in a highly asymmetric environment. The overall shape of the spectrum is determined by the isotropic chemical shift value $\delta_{\text {iso, }}$, the quadrupole coupling constant $C_{\mathrm{Q}}$ and asymmetry parameter of electric field gradient $\eta$, as well as by the distribution of these parameters in structurally inhomogeneous samples. 


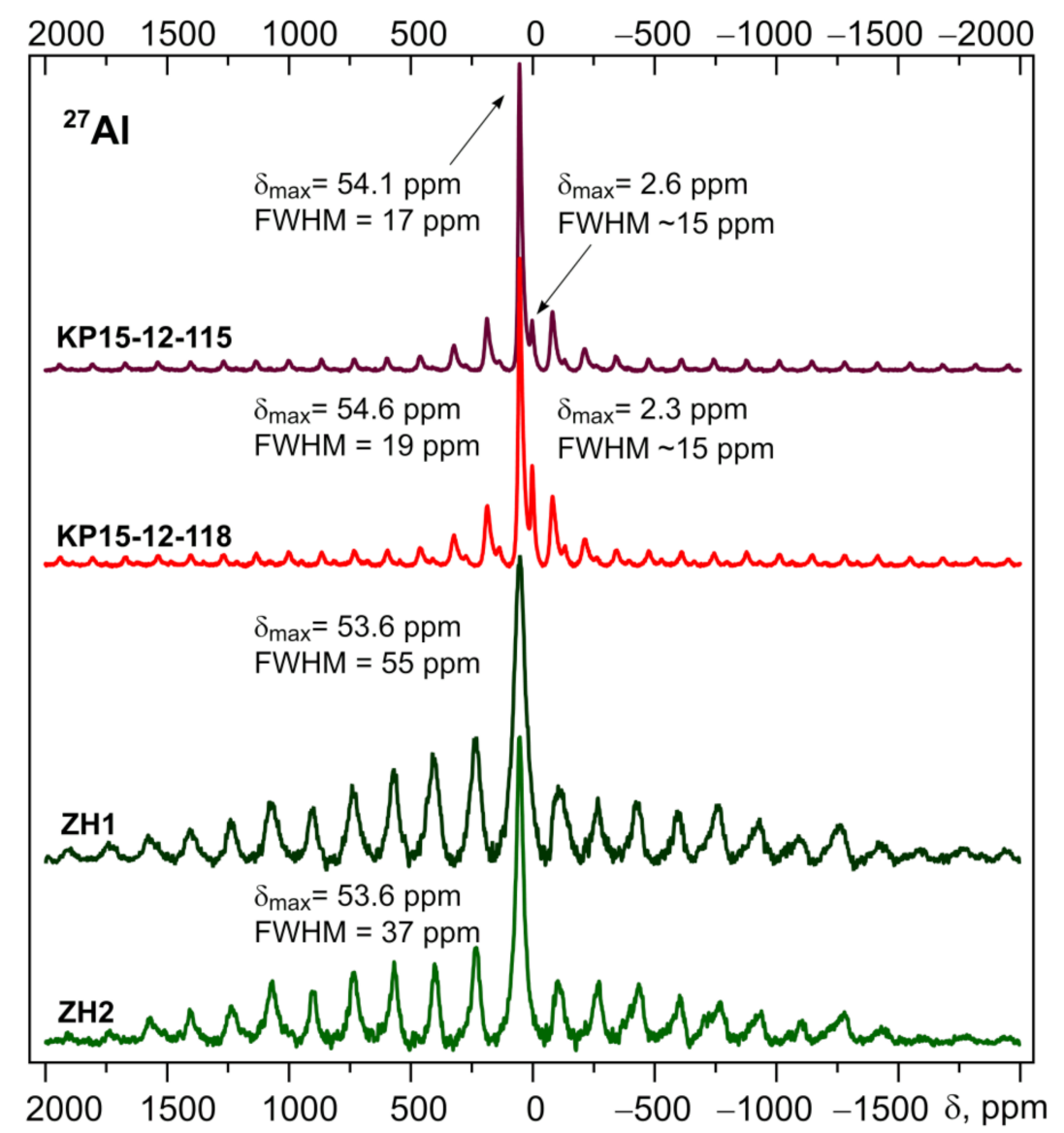

Figure 2. Overview ${ }^{27} \mathrm{Al}$ MAS NMR spectra of KP15-12-115, KP15-12-118, ZH1 and ZH2 samples in the range of chemical shifts from $-2000 \mathrm{ppm}$ to $2000 \mathrm{ppm}$. The positions of the maxima of the central bands and their FWHM measured by the spectral contour are presented.

The central (isotropic) parts of ${ }^{27} \mathrm{Al}$ NMR spectra of Kara glasses are characterized by intensive signals with maxima at ca. $54 \mathrm{ppm}$ and additional low-intensity signals at 2-3 ppm. The full width at a half-maximum (FHWM) of both components is less than $20 \mathrm{ppm}$. All signals are slightly asymmetric, so their centers of gravity are shifted to lower frequencies from the maxima which indicates the presence of the second-order quadrupole effects $[24,25]$. The main signal at 50-60 ppm corresponds to aluminum atoms with 4-fold coordination to oxygen ( ${ }^{\mathrm{IV}} \mathrm{Al}$, tetrahedral coordination; most likely $\left(\mathrm{AlO}_{4} \mathrm{Q}^{4}[4 \mathrm{Si}]\right)$, more on that later). Frequently, this is the only coordination state of aluminum in high-silicon aluminosilicate glasses, to which the studied samples belong too [26]. Previously, the signal from five-coordinated ${ }^{\mathrm{V}} \mathrm{Al}\left(\mathrm{AlO}_{5}\right)$ atoms was also detected in high-pressure aluminosilicate glass by the ${ }^{27} \mathrm{Al}$ MAS NMR [27-29], though the corresponding signal at 20-40 ppm, which is a typomorphic feature of fresh impact glass, is apparently absent in the ${ }^{27} \mathrm{Al} N \mathrm{NR}$ spectra of the samples studied here. A possible reason may be the prolonged relaxation of the impact glass at high temperatures. In turn, the low-intensity signal at chemical shift $2-3$ ppm is explained by hexacoordinated ${ }^{\mathrm{VI}} \mathrm{Al}[26,30-32]$. The intensity of this signal in the spectrum of the KP15-12-118 sample is 2-3 times higher than that of the spectrum of the KP15-12-115 sample.

The shapes of the central components of the spectra are repeated in the shapes of the spinning sidebands, which could be labelled as 0 (central component), $\pm 1, \pm 2$, etc., and traced up to $\pm 4000 \mathrm{ppm}$. It is well known that the presence of paramagnetic Fe ions in the vicinity of the observed nuclei causes the transfer of intensity from ssb 0 to the low-order ssb [27,33]. Judging from the sample composition outlined in Table 1, such effects are expected to be present in the Kara glass samples. It also should be noted that for high-pressure aluminosilicate glass with $5 \mathrm{wt} . \% \mathrm{FeO}$ [27], the paramagnetic broadening of 
the isotropic central signal and the intensity of the nearest ssb in ${ }^{27} \mathrm{Al}$ MAS NMR spectra were noticeably higher than those found here in the Kara glass spectra, although the $\mathrm{FeO}$ content for the Kara glasses was even higher (5.5-6.5 wt.\%, see Table 1). This allows us to conclude that the $\mathrm{Al}$ and $\mathrm{Fe}$ atoms are spatially separated in the structure of the Kara glass. Since the main ${ }^{27} \mathrm{Al}$ MAS NMR signal corresponds to the tetrahedral ${ }^{\mathrm{IV}} \mathrm{Al}$ coordination, the Fe ions do not belong to the compensators of the local negative excess charge of $\left[\mathrm{AlO}_{4}\right]$ units, although Fe ions occupy mainly octahedral positions according to the Mössbauer spectroscopy data [14].

In the ${ }^{27} \mathrm{Al}$ MAS NMR spectra of samples ZH1 and ZH2, only one isotropic signal from tetrahedrally coordinated ${ }^{\mathrm{IV}} \mathrm{Al}$ atoms is visible at ca. $53.6 \mathrm{ppm}$. Despite the lower $\mathrm{FeO}$ content in the zhemanshinites as compared to the Kara glasses, the effects of paramagnetic broadening are much more pronounced: all signals exhibit FWHM 2-3 times higher than that for the Kara glasses and the ssb signals have a higher intensity relative to the central band. Due to this broadening, the shape of the central band is almost symmetric: the centers of gravity are at 52-53 ppm, only slightly lower than the chemical shifts of the maxima. Again, the presence of ${ }^{\mathrm{V}} \mathrm{Al}$ ions was not detected, probably because of the low spectral resolution due to the strong paramagnetic broadening of the signals. Unfortunately, for all the studied samples, the low amount of the material with the low content of ${ }^{\mathrm{V}} \mathrm{Al}$ phases and the presence of paramagnetic impurities did not allow us to record ${ }^{27} \mathrm{Al}$ MQMAS spectra.

\section{3. ${ }^{23} \mathrm{Na}$ MAS NMR}

The ${ }^{23} \mathrm{Na}$ spectra of the studied samples (Figure 3) demonstrate narrow intense central bands and $\pm 1, \pm 2 \mathrm{ssb}$. Higher-order ssb get progressively less intensive, though their presence could be traced up to $\pm 2000 \mathrm{ppm}$. The low-order ssb refer mainly to the $( \pm 1 / 2$, $\pm 1 / 2)$ transition, while the high-order ssb refer to the $( \pm 3 / 2, \pm 1 / 2)$ transition of the quadrupolar ${ }^{23} \mathrm{Na}$ nuclei (spin I = 3/2).

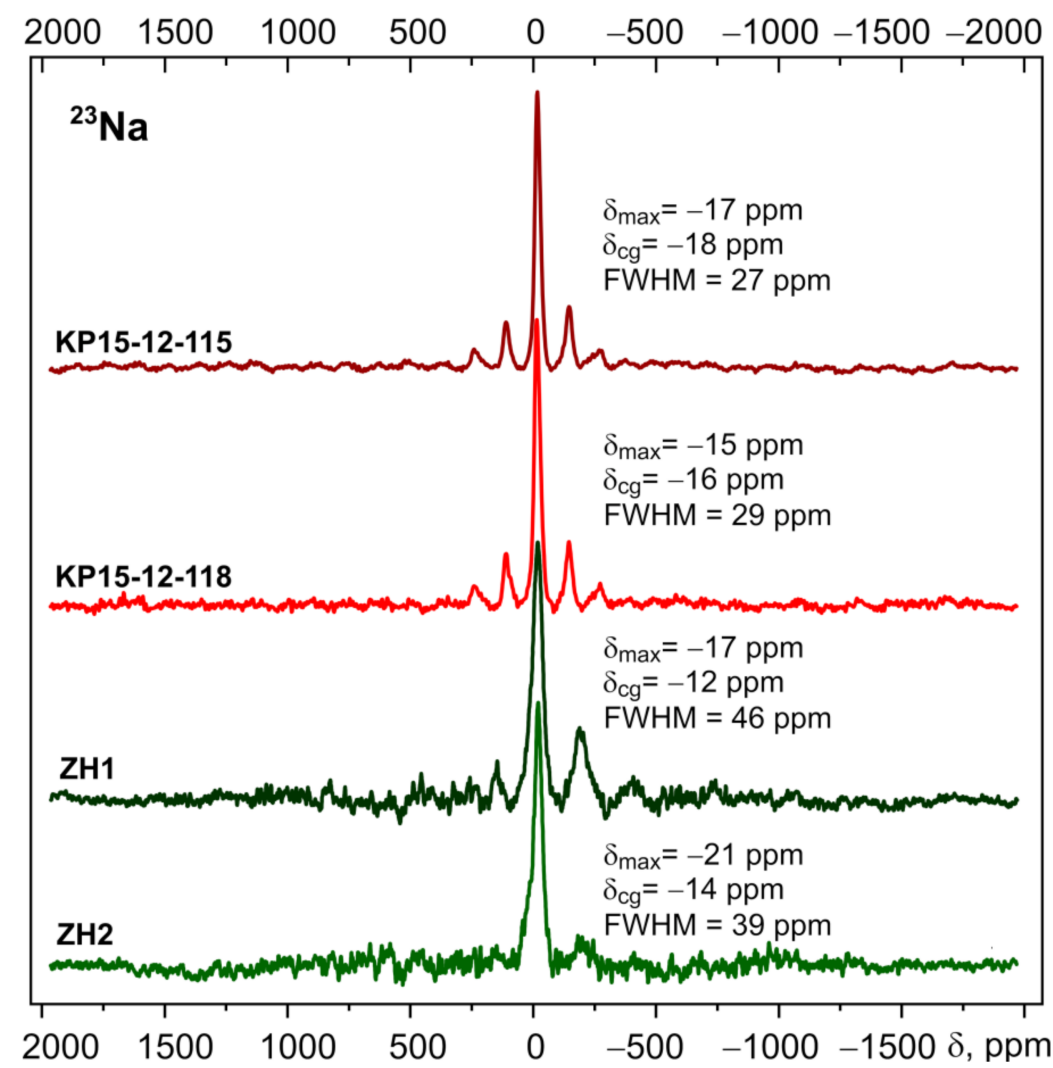

Figure 3. Overview ${ }^{23} \mathrm{Na}$ MAS NMR spectra of the impact glasses. The positions of the maxima and the centers of gravity of the central bands, as well as their FWHM values, are given. 
The ${ }^{23} \mathrm{Na}$ NMR spectra of the Kara glasses show a small transfer of the intensity from the central band in the nearest ssb, which, as already noted, is one of the paramagnetic effects from Fe ions. The positions of the gravity centers of the central bands are slightly shifted towards lower frequencies relative to their maxima (Figure 3), which shows a greater contribution to the signal broadening due to the second-order quadrupole effects than due

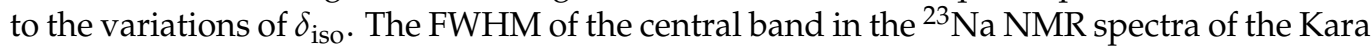
glasses is close to $30 \mathrm{ppm}$. The ${ }^{23} \mathrm{Na}$ NMR spectra of the zhamanshinite samples exhibit broader central bands (FWHM $=46$ and $39 \mathrm{ppm}$ ) and only low-order ssb, mainly related to the $( \pm 1 / 2, \pm 1 / 2)$ transition. The positions of the centers of gravity of the central bands are noticeably shifted towards higher frequencies relative to their maxima, which indicates the dominance of the broadening mechanism due to variations in the isotropic chemical shift. For both the Kara glass and the zhamanshinite samples, the FWHM of central bands in the ${ }^{27} \mathrm{Al}$ and ${ }^{23} \mathrm{Na} \mathrm{NMR}$ spectra change synchronously (Figure 4 ). This probably indicates to the co-localization of $\mathrm{Al}$ and $\mathrm{Na}$ ions in the aluminosilicate glass network, which is realized according to the scheme of heterovalent isomorphism in tetrahedral positions, when $\mathrm{Na}^{+}$ions play the role of compensators of the local negative charge excess: $\mathrm{Si}^{4+} \mathrm{O}_{4} \rightarrow \mathrm{Al}^{3+} \mathrm{O}_{4}+\mathrm{Na}^{+}$.

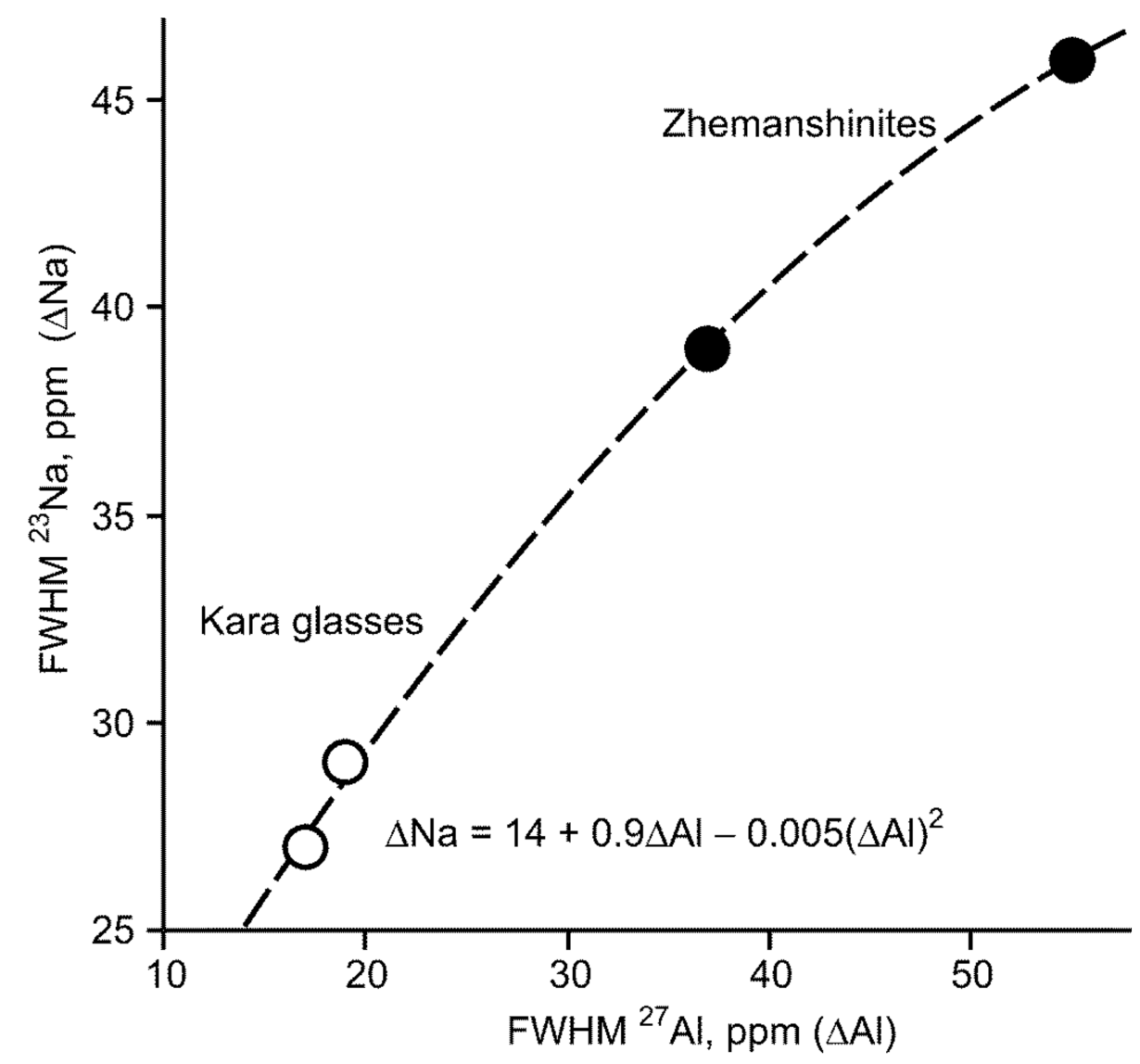

Figure 4. The FWHM plot of the ${ }^{23} \mathrm{Na}$ NMR central bands vs. FWHM of the ${ }^{27} \mathrm{Al}$ NMR central bands of the impact glasses.

\section{4. ${ }^{29}$ Si MAS NMR}

The ${ }^{29} \mathrm{Si}$ NMR spectra of the studied samples are shown in the Figure 5, where an intensive central line and low-intensity ssb of low orders are observed. There are no quadrupole effects in the NMR spectra of the spherical ${ }^{29}$ Si nuclei (spin 1/2) and only a wide isotropic central signal spanning from -60 ppm to -120 ppm could be observed. The maximum of the central band of the sample ZH2 is near to -105 ppm, and in other samples it is shifted to -100 ppm (the positions of maxima and centers of gravity are added to Figure 5). This range of chemical shifts is a characteristic for syloxane $\mathrm{SiO}_{4}$-structures, 
polymerized to various degrees [26]. There are no observed additional signals in the spectral range from $-150 \mathrm{ppm}$ to $-200 \mathrm{ppm}$, characteristics for $\mathrm{SiO}_{5}$ or $\mathrm{SiO}_{6}$ structural units, previously found in some high-pressure glasses [28].

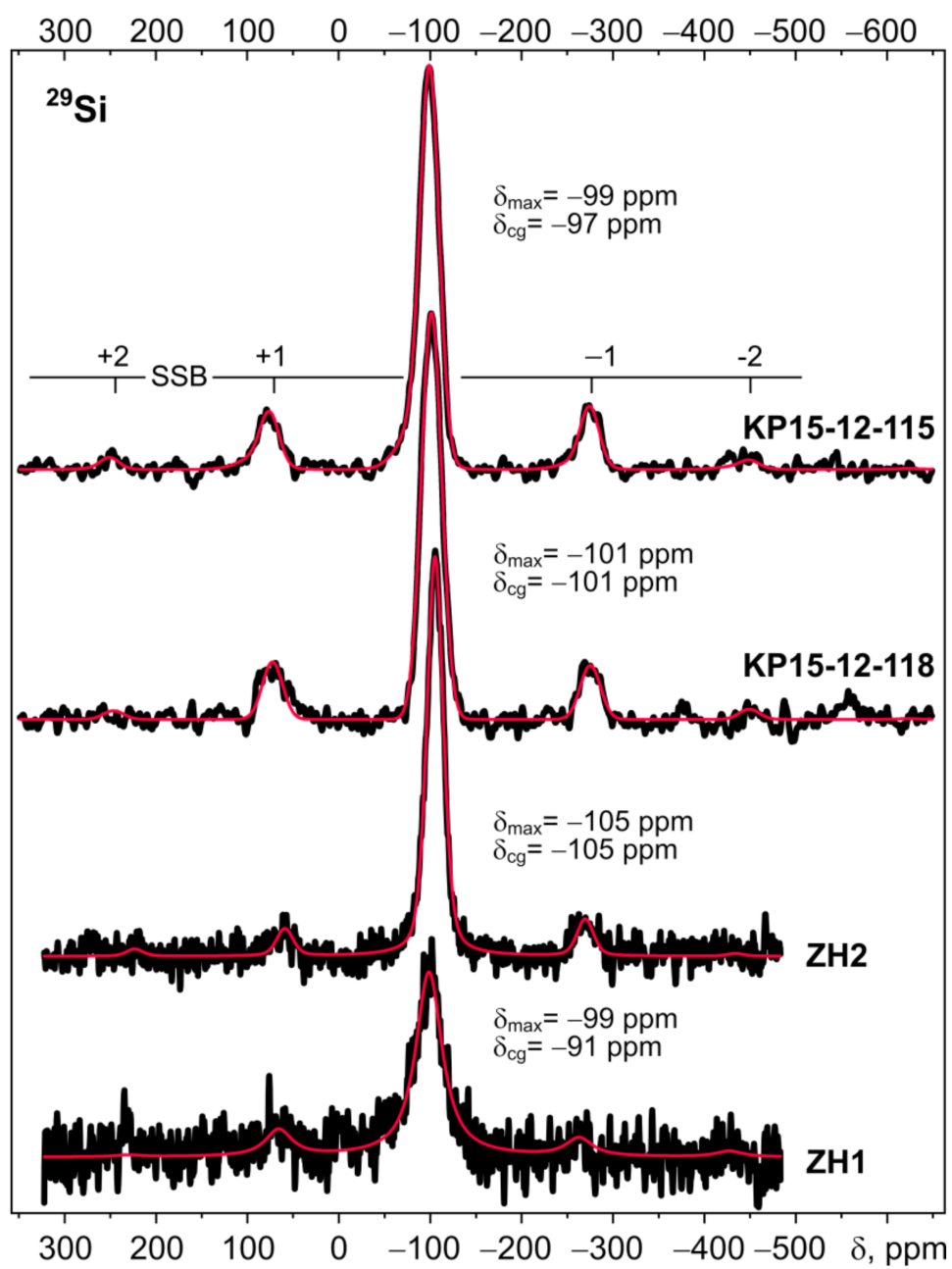

Figure 5. The overview ${ }^{29} \mathrm{Si}$ MAS NMR spectra of the studied glasses. Black line-experimental, and red lines-fitted spectra.

\section{Discussion}

When interpreting ${ }^{27} \mathrm{Al}$ MAS NMR spectra of the analyzed impact glass materials, the simplest physically consistent Gaussian isotropic model (GIM), also called the Czjzek model, is widely used. In this model, it is assumed that the distribution of the electric field gradient tensor corresponds to statistical disorder [34,35]. This assumption determines the probability of finding a given pair of values $C_{\mathrm{Q}}$ and $\eta$. The Czjzek model is implemented in DMFit software [22] which we have used to fit the experimentally obtained spectra. For nuclei with a spin $5 / 2$, such as ${ }^{27} \mathrm{Al}$, the isotropic signal in an MAS NMR spectrum arises predominantly due to the transition $( \pm 1 / 2, \pm 1 / 2)$, while the ssb components arise mainly due to the $( \pm 3 / 2, \pm 1 / 2)$ and $( \pm 5 / 2, \pm 3 / 2)$ transitions. The contribution of the second-order terms of quadruple interaction is smaller in the $( \pm 3 / 2, \pm 1 / 2)$ transition and its ssb components are less susceptible to broadening $[24,36,37]$. Note, however, that it is difficult to reproduce the actual intensity and shape of the ssb $0, \pm 1$, and \pm 2 in the fitting procedure, due to the above-mentioned effect of intensity redistribution caused by the proximity of paramagnetic ions. Thus, in this work, the determination of the distribution of $\mathrm{Al}$ atoms over structural positions in the matrices of the studied glasses was carried out on the basis of the analysis of the shape of the central band. We used the fitting in the Czjzek model for the $( \pm 1 / 2, \pm 1 / 2)$ transition only. The contributions of other transitions 
were taken into account by adding an additional signal of the ssb 0 to the calculated contour, obtained as the average between ssb +1 and ssb -1 components, approximated by symmetric Voigt shapes. This approach is widely used in the analysis of various glassy substances to describe the central line in ${ }^{27} \mathrm{Al}$ MAS NMR spectra $[35,36,38]$.

The results of the fitting are shown in Figure 6 and the obtained spectral parameters are collected in Table 2. The average value of the asymmetry parameter of electric field gradient $\eta$ in this approximation was found to be 0.61 . The ${ }^{\mathrm{VI}} \mathrm{Al}$ signals (labelled $\mathrm{Px}$ ) in the spectra of both Kara glass samples are characterized by almost identical values to the isotropic chemical shifts $\delta_{\text {iso }}$ (ca. $8 \mathrm{ppm}$ ), the widths of their Gaussian distributions $\Delta_{\mathrm{CS}}$ (ca. $8 \mathrm{ppm}$ ), and the quadrupole coupling constants $C_{\mathrm{Q}}$ (ca. $3.8 \mathrm{MHz}$ ). The Px components differ significantly in the relative intensity, which is twice as high for the KP15-12-118 sample, as for KP15-12-115. It is likely that the ${ }^{\mathrm{VI}} \mathrm{Al}$ components in the spectra refer to numerous precipitates in pyroxene glasses $[13,16]$ and not to the matrix of the aluminosilicate glass network because the fitted NMR parameters are close to those calculated previously for ${ }^{\mathrm{VI}} \mathrm{Al}$ in completely disordered octahedral sites of pyroxene $[39,40]$.

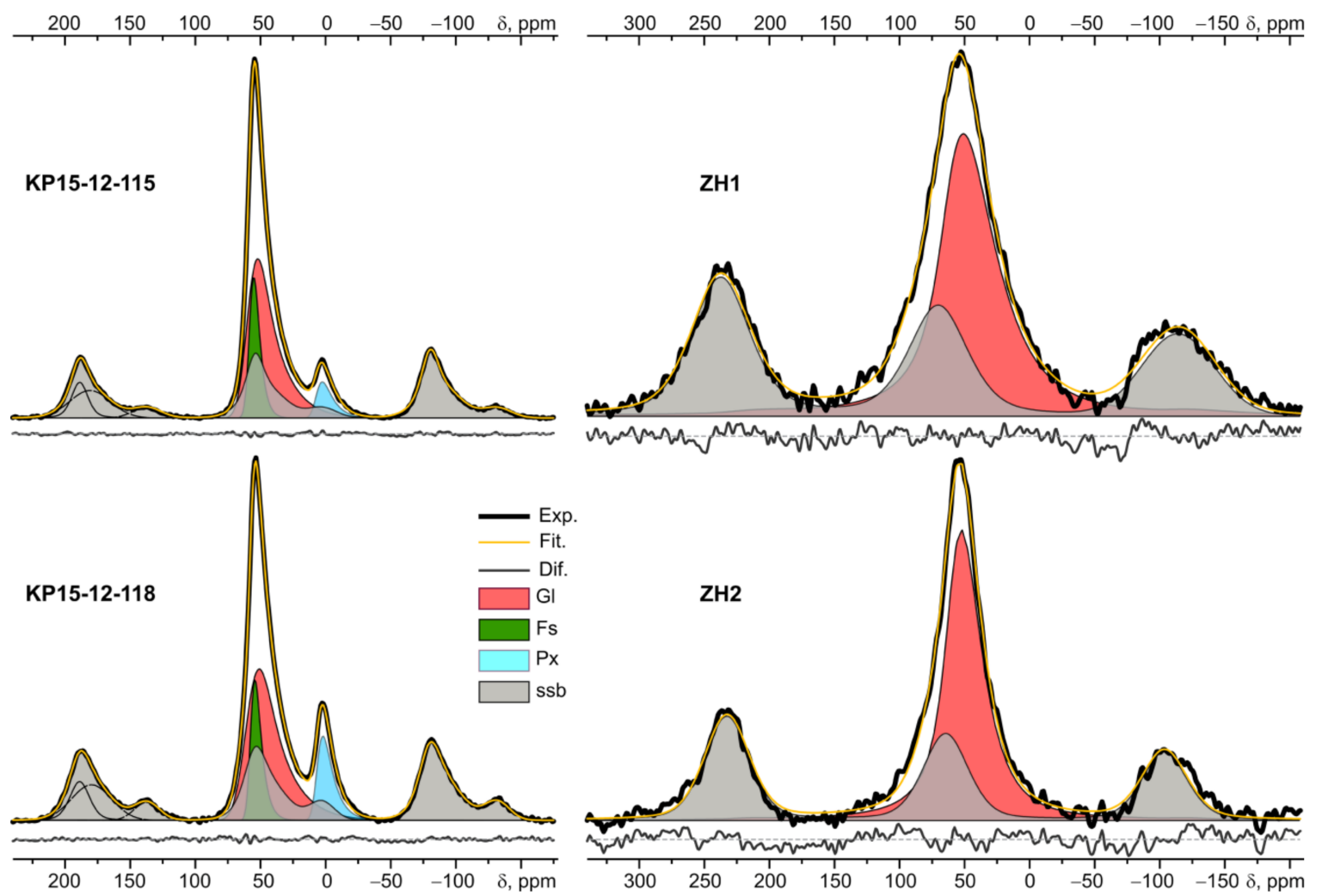

Figure 6. Deconvolution of the central band of the ${ }^{27} \mathrm{Al}$ MAS NMR spectra: Exp.-experimental spectra; Fit.-full deconvolution spectra; Dif.—difference (Exp.—Fit.); Gl, Fs, and Px are Czjzek components; ssb—spinning sidebands approximated by the superposition of Voigt line shapes (three components for the Kara glass samples, and one component for zhamanshinites). For the fitting of ZH1 and ZH2 spectra, the ssb components of the central transition $( \pm 1 / 2, \pm 1 / 2)$ were included in the Czjzek model.

Two components with Gaussian distributions of $\delta_{\text {iso }}$ and $C_{Q}$ values are required for a reasonably good fit of the ${ }^{\mathrm{IV}} \mathrm{Al}$ signal at ca. $60 \mathrm{ppm}$. The narrower component (labelled Fs) has $C_{\mathrm{Q}} \sim 3 \mathrm{MHz}, \delta_{\text {iso }} \sim 58 \mathrm{ppm}, \Delta_{\mathrm{CS}} \sim 7 \mathrm{ppm}$, and the broader component (labelled Gl) has $\mathrm{C}_{\mathrm{Q}} \sim 5-6 \mathrm{MHz}, \delta_{\text {iso }} \sim 62 \mathrm{ppm}, \Delta_{\mathrm{CS}} \sim 14-18 \mathrm{ppm}$ with an approximately three times larger spectral area (Table 2). The presence of Fs and Gl components indicates the microscopically inhomogeneous structure of the Kara glasses. Both components belong to the ${ }^{\mathrm{IV}} \mathrm{Al}$ in the aluminosilicate framework and not to the tetrahedral positions in pyroxene precipitates. According to microprobe studies, the composition of pyroxene (augite) in the Kara glass 
suggests the absence of noticeable amounts of ${ }^{\mathrm{IV}} \mathrm{Al}$ [14]. Indeed, it is expected that the signal from the latter is strongly broadened due to the high value of $C_{Q}$ and, thus, has low peak intensity $[39,40]$. The ${ }^{\mathrm{IV}} \mathrm{Al}$ signal in pyroxene may be unobservable due to the high paramagnetic intensity loss during the charge compensation of the heterovalent substitution of $\mathrm{Al}^{3+} \rightarrow \mathrm{Si}^{4+}$ by $\mathrm{Fe}^{2+}$ ions in neighboring octahedral positions [41,42].

Table 2. The fitted Czjzek parameters of components of the ${ }^{27} \mathrm{Al}$ MAS NMR of the impact glasses.

\begin{tabular}{|c|c|c|c|c|c|}
\hline Samples & Components & $\delta_{\text {iso, }}, \mathrm{ppm}$ & $\Delta_{\mathrm{CS}}, \mathrm{ppm}$ & $C_{\mathrm{Q}}, \mathrm{MHz}$ & A, \% \\
\hline \multirow{3}{*}{ KP15-12-115 } & $\mathrm{Px},{ }^{\mathrm{VI}} \mathrm{Al}$ & $8.2 \pm 0.4$ & $8 \pm 1$ & $3.8 \pm 0.2$ & $9 \pm 1$ \\
\hline & $\mathrm{Fs}_{\mathrm{s}}{ }^{\mathrm{IV}} \mathrm{Al}$ & $58.8 \pm 0.1$ & $7 \pm 1$ & $2.7 \pm 0.1$ & $23 \pm 4$ \\
\hline & $\mathrm{Gl}^{\prime}{ }^{\mathrm{IV}} \mathrm{Al}$ & $62 \pm 1$ & $14 \pm 1$ & $5.4 \pm 0.1$ & $68 \pm 4$ \\
\hline \multirow{3}{*}{ KP15-12-118 } & $\mathrm{Px},{ }^{\mathrm{VI}} \mathrm{Al}$ & $7.6 \pm 0.3$ & $7.4 \pm 0.7$ & $3.7 \pm 0.1$ & $17 \pm 1$ \\
\hline & $\mathrm{Fs},{ }^{\mathrm{IV}} \mathrm{Al}$ & $58.1 \pm 0.2$ & $6 \pm 1$ & $2.9 \pm 0.2$ & $19 \pm 2$ \\
\hline & $\mathrm{Gl},{ }^{\mathrm{IV}} \mathrm{Al}$ & $63 \pm 1$ & $18 \pm 1$ & $5.7 \pm 0.2$ & $64 \pm 2$ \\
\hline $\mathrm{ZH} 1$ & $\mathrm{Gl},{ }^{\mathrm{IV}} \mathrm{Al}$ & $65 \pm 4$ & $33 \pm 1$ & $5.5 \pm 0.1$ & 100 \\
\hline $\mathrm{ZH} 2$ & $\mathrm{Gl}^{\mathrm{IV}} \mathrm{Al}$ & $61.1 \pm 0.3$ & $23 \pm 1$ & $4.1 \pm 0.1$ & 100 \\
\hline
\end{tabular}

Note. $\delta_{\text {iso }}$ is the isotropic chemical shift, $\Delta_{\mathrm{CS}}$ is the width (FWHM) of the Gaussian distribution of $\delta_{\text {iso, }} C_{\mathrm{Q}}$ is the quadrupole coupling constant, and $\mathrm{A}$ is the relative area of the corresponding component.

The isotropic chemical shift $\delta_{\text {iso }} \sim 60$ ppm of the narrow Fs component is typical for frame aluminosilicates and fully polymerized aluminosilicate glasses in the structure of which all or almost all oxygen atoms of the $\mathrm{AlO}_{4}$ tetrahedra are in bridging $[35,37,43]$. This signal appears to be related to crystalline feldspars [24]. Inclusions of various feldspars are well detected by microscopy and XRD methods in preparations of vein Kara glass, even when thoroughly cleaned of foreign inclusions [14,16]. Fine grains of minerals, including feldspars, were captured from the host suvites during the movement of the hot aluminosilicate melt at the post-shock stage.

According to Table 2, about $70 \%$ of the area of the central band belongs to the aluminosilicate phase (Gl) of the Kara glass samples. However, the atomic fraction of $\mathrm{Al}$ in a certain position is given by the relative area of the corresponding spectral component including all its ssb lines. Such a correction performed by the method described D. Massiot with co-authors in [44], showed that the contribution of the Gl components should be increased by $2 \%-3 \%$ and, accordingly, the contribution from the crystal phases should be reduced. With this in mind, we take the value of $70 \%$ as the lower limit of the atomic fraction of $\mathrm{Al}$ in the glass matrix. The high values of the relative area of the Fs component are associated with small intensity loss of the central line in comparison with the Gl and Px components, due to the low value of the $C_{Q}$ and, probably, low concentrations of iron in the mineral lattice.

In the ${ }^{27} \mathrm{Al}$ MAS NMR spectra of the samples $\mathrm{ZH} 1$ and $\mathrm{ZH} 2$, the central bands are strongly broadened and could be fitted by a single component (Figure 6). Within the error margin, the fitted values of $C_{Q}$ and $\delta_{\text {iso }}$ do not differ from those of Gl components of the Kara glass spectra (Table 2). The width of the chemical shift distribution $\Delta_{\mathrm{CS}}$ for the zhemanshinite samples is much higher than that for the Kara glasses, which indicates more clustering of $\mathrm{Al}$ and Fe atoms in the LP tektite glass framework. This conclusion does not contradict the results of the study of the zhemanshinites by high-resolution microscopy [21].

The deconvolution of the ${ }^{23} \mathrm{Na} N \mathrm{NMR}$ central bands and the nearest ssb are shown in Figure 7. To approximate the spectra, the GIM model was used, which had included all spin transitions for the ${ }^{23} \mathrm{Na}$ nuclei, $( \pm 1 / 2, \pm 1 / 2)$ and $( \pm 3 / 2, \pm 1 / 2)$, as well as their spinning sidebands. For the spectrum of the KP15-12-115 sample, the individual components for each of the transitions are shown. The GIM model reproduces the shape of the central band quite well, but the calculated ssb contour is greatly underestimated due to the low intensity of the ssb $( \pm 1 / 2, \pm 1 / 2)$ transition. To compensate for the missing intensity of the 
bands, an additional pair of Lorentzian shape lines in positions of ssb $( \pm 1 / 2, \pm 1 / 2)$ was introduced into the calculation model.
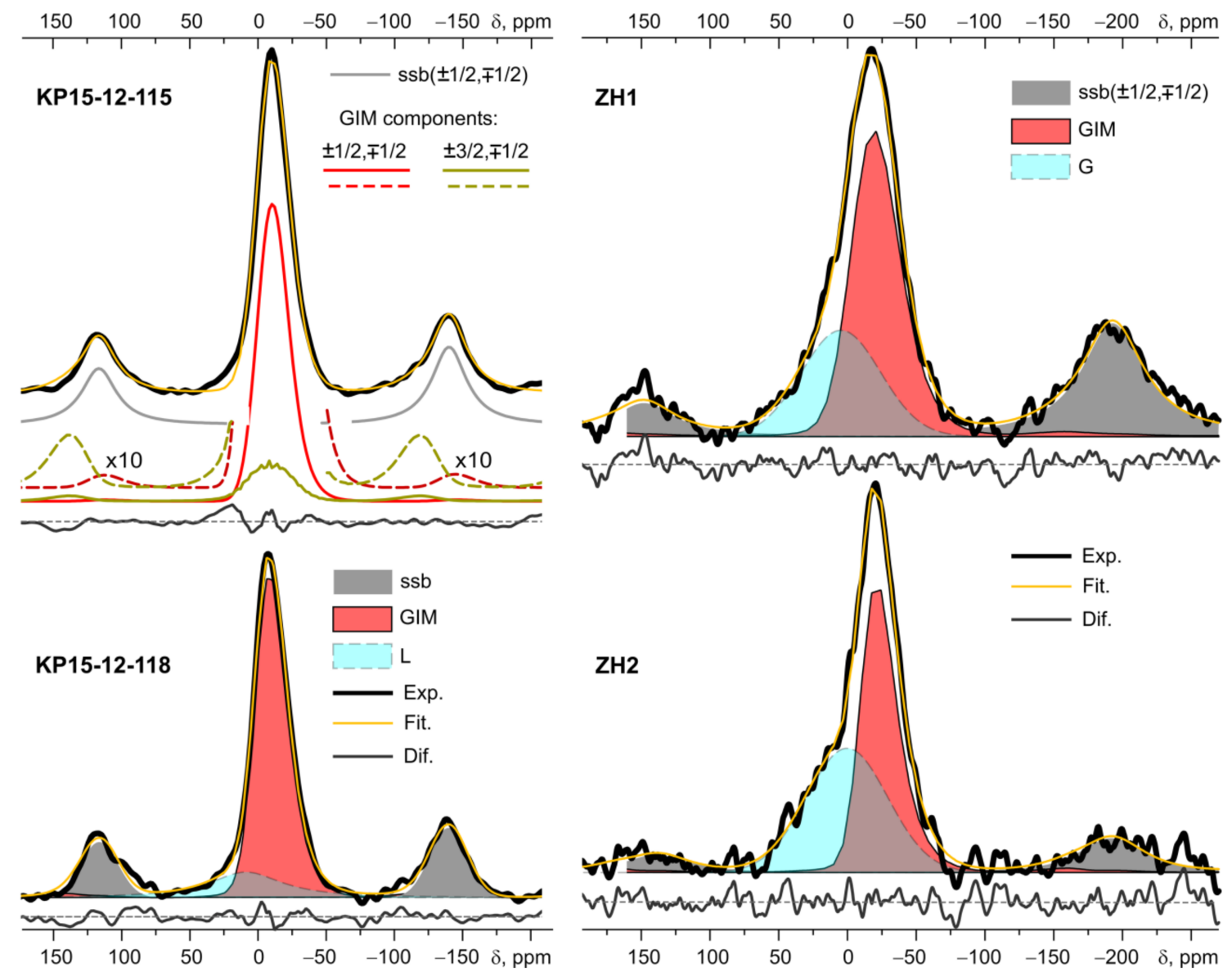

Figure 7. Deconvolution of the ${ }^{23}$ Na MAS NMR spectra: Exp.--experimental spectra; Fit.-full deconvolution spectra; Dif.-difference (Exp.-Fit.); GIM-Czjzek component (all transitions of the central band and ssb); ssb-additional spinning sidebands approximated by the Voigt line shape; L or G-additional Lorentzian or Gaussian components of the central bands. For the KP15-12-115 spectrum, individual components for each of the transitions are shown, supplemented by a pair of lines (ssb ( $\pm 1 / 2, \pm 1 / 2)$ ), which compensates for the insufficient calculated intensity of the sidebands.

Some residual intensity in the difference spectrum (Dif. in Figure 7) is found for the sample KP15-12-115 in the region of zero chemical shifts. In the spectrum KP15-12118 , the discrepancy is sufficiently large to justify the addition of a small component of the Lorentzian shape in the high-frequency wing of the central line. In the spectra of the zhamanshinites, such additional components acquire a high intensity, accounting for almost half of the area of the central line. Perhaps these additional lines are due to the paramagnetic shift of the signal from ${ }^{23} \mathrm{Na}$ nuclei in the immediate environment of which iron ions are present. In Fe-containing minerals, a shift in the position of peaks ${ }^{29} \mathrm{Si},{ }^{27} \mathrm{Al}$, and the appearance of anomalous resonances outside the assumed range were observed [41,42].

The fitted ${ }^{23} \mathrm{Na}$ MAS NMR parameters are listed in Table 3 . The $\delta_{\text {iso }}$ values of all main central lines (GIM components) lie in a narrow range from $-6 \mathrm{ppm}$ to $-10 \mathrm{ppm}$. The $C_{\mathrm{Q}}$ values are ca. $2 \mathrm{MHz}$ and fall in the 1.5-3.5 MHz range for Na-containing silicates. They are slightly lower than the typical value of $3.3 \mathrm{MHz}$ for crystalline aluminosilicates but are close to the characteristic value of $2.5 \mathrm{MHz}$ for aluminosilicate glasses $[24,30,45,46]$. 
Table 3. The fitted parameters of the ${ }^{23} \mathrm{Na}$ MAS NMR of the impact glasses.

\begin{tabular}{cccccc}
\hline Sample & Component & $\boldsymbol{\delta}_{\text {iso, }} \mathbf{p p m}$ & $\boldsymbol{\Delta}_{\mathbf{C S}}, \mathbf{p p m}$ & $\boldsymbol{C}_{\mathbf{Q}}, \mathbf{M H z}$ & $\mathbf{A}, \mathbf{\%}$ \\
\hline \multirow{2}{*}{ KP15-12-115 } & GIM & $-9.0 \pm 0.3$ & $22 \pm 1$ & $1.9 \pm 0.1$ & 100 \\
\hline \multirow{2}{*}{ KP15-12-118 } & GIM & $-6.2 \pm 0.5$ & $20 \pm 2$ & $2.1 \pm 0.2$ & $82 \pm 3$ \\
& L & $3 \pm 8$ & $65 \pm 20$ & - & $18 \pm 4$ \\
\hline \multirow{2}{*}{ ZH1 } & GIM & $-6 \pm 1$ & $32 \pm 1$ & $2.5 \pm 0.3$ & $66 \pm 5$ \\
& G & $5 \pm 4$ & $67 \pm 7$ & - & $34 \pm 5$ \\
\hline \multirow{2}{*}{ ZH2 } & GIM & $-10 \pm 1$ & $20 \pm 1$ & $2.4 \pm 0.3$ & $54 \pm 5$ \\
& G & $0 \pm 2$ & $70 \pm 10$ & - & $46 \pm 5$ \\
\hline
\end{tabular}

Note. $\delta_{\text {iso }}$ is the isotropic chemical shift, $\Delta_{\mathrm{CS}}$ is the width (FWHM) of the Gaussian distribution of $\delta_{\text {iso }}, \mathrm{C}_{\mathrm{Q}}$ is the quadrupole coupling constant, $\mathrm{A}$ is the relative area of the corresponding component; $\mathrm{L}$ or $\mathrm{G}$ is the additional Lorentzian or Gaussian components of the central bands.

The value of the ${ }^{23} \mathrm{Na}$ NMR isotropic chemical shift in aluminosilicates or their glasses decreases with a decrease in the $\mathrm{Al} /(\mathrm{Si}+\mathrm{Al})$ atomic ratio, which is explained by a concomitant increase in the coordination number of $\mathrm{Na}$ atoms and an increase of the $\mathrm{Na}-\mathrm{O}$ bond length $[30,45-47]$. However, though the samples of the zhamanshinites are more siliceous in comparison with the Kara glasses (Table 1), no significant difference in $\delta_{\text {iso }}$ was found. This can be explained partly by the presence of a significant portion of $\mathrm{Al}$ in the crystalline phases rather than in the aluminosilicate glass in the Kara samples (Table 2).

The range of $\delta_{\text {iso }}$ from $-6 \mathrm{ppm}$ to $-10 \mathrm{ppm}$ corresponds to crystalline aluminosilicates with 6-8-fold coordination of ${ }^{23} \mathrm{Na}$ atoms with $\mathrm{Na}$-O bond length of about $0.26 \mathrm{~nm}$, among them feldspars [47]. It is not possible to deconvolute the ${ }^{23} \mathrm{Na}$ NMR signals from glass and crystalline phases of aluminosilicates in the Kara glasses due to small differences in their $C_{\mathrm{Q}}$ and $\delta_{\text {iso }}$ values. However, judging by the relative signal areas in ${ }^{27} \mathrm{Al}$ NMR spectra (Table 2), the contribution from crystalline aluminosilicate phases in the ${ }^{23} \mathrm{Na}$ NMR spectra should be relatively small.

According to the regression equation $\delta_{\text {iso }}$ vs. $\mathrm{Na}-\mathrm{O}$ bond length for aluminosilicate glasses [45], the average Na-O distance for the GIM components is $0.27-0.28 \mathrm{~nm}$, which is close to the calculated values for 6-8-fold $\mathrm{Na}$ coordination in association with [Si,Al] $\mathrm{O}_{4}$ structural units of the glass network $[45,46]$. The high coordination of $\mathrm{Na}$ atoms in the impact glass network indicates their role as compensator ions for tetrahedral $\mathrm{Al}^{3+}$ ions. Note that previously Mössbauer spectroscopy has revealed a small amount of $\mathrm{Fe}^{2+}$ ions in 8 -fold oxygen coordination in the Kara glasses, but not in the zhamanshinites [14,15]. An additional strongly broadened L or G component in the spectra shown in Figure 7 could be assigned to the $\mathrm{Na}$ atoms in the clustering regions of $\mathrm{Al}$ and $\mathrm{Fe}$ atoms. A high proportion of $\mathrm{Na}$ atoms in such an environment is a characteristic of the zhamanshinite.

In comparison with the studied impact glasses, the isotropic values of ${ }^{29} \mathrm{Si} \mathrm{NMR}$ chemical shifts of fused and diaplectic $Q^{4}$ quartz glasses are more negative, $-111.5 \mathrm{ppm}$ and $-107.85 \mathrm{ppm}$, respectively, and the signals exhibit significantly smaller line widths, 12-17 ppm, according to [48]. It can be assumed that the differences in the positions and widths of the lines are associated with incomplete polymerization of the $\mathrm{SiO}_{4}$ framework of the impact glass and the presence of $\mathrm{Q}^{3}$ and $\mathrm{Q}^{2}$ configurations in its structure, characterized by the isotropic chemical shift in the range from $-80 \mathrm{ppm}$ to $-100 \mathrm{ppm}$ [49]. Indeed, previously, based on the Raman data, a significant dispersion of the polymerization degree of $\mathrm{SiO}_{4}$ tetrahedra in the impact glass was suggested [16]. The overall composition of the samples (Table 1) indicates that the degree of polymerization of the Kara glasses, like that of the zhamanshinites, is close to the maximum value of $\mathrm{Q}^{4}(\mathrm{NBO} / \mathrm{T} \leq 0.3)$ and the ${ }^{27} \mathrm{Al}$ NMR spectra showed that aluminum atoms have tetrahedral coordination. Thus, the ${ }^{29} \mathrm{Si}$ NMR chemical shift could be described in terms of $\mathrm{Q}^{4}(m \mathrm{Al})$ structural units, where $m=0-4$ is the number of aluminum atoms in the nearest environment of $\mathrm{Si}$ [26]. As the number of $\mathrm{Al}$ atoms in the environment of $\mathrm{Si}$ increases, the chemical shift becomes less negative (i.e., increases). The corresponding spectral ranges are shown in Figure 8 as horizontal blue bars. The central bands of the ${ }^{29} \mathrm{Si}$ NMR spectra could then be described as superpositions 
of individual $\mathrm{Q}^{4}(\mathrm{mAl})$ bands. The maxima of the central bands correspond to the average configurations $\mathrm{Q}^{4}(1 \mathrm{Al})$ for $\mathrm{ZH} 2$ and $\mathrm{Q}^{4}(2 \mathrm{Al})$ for other samples.

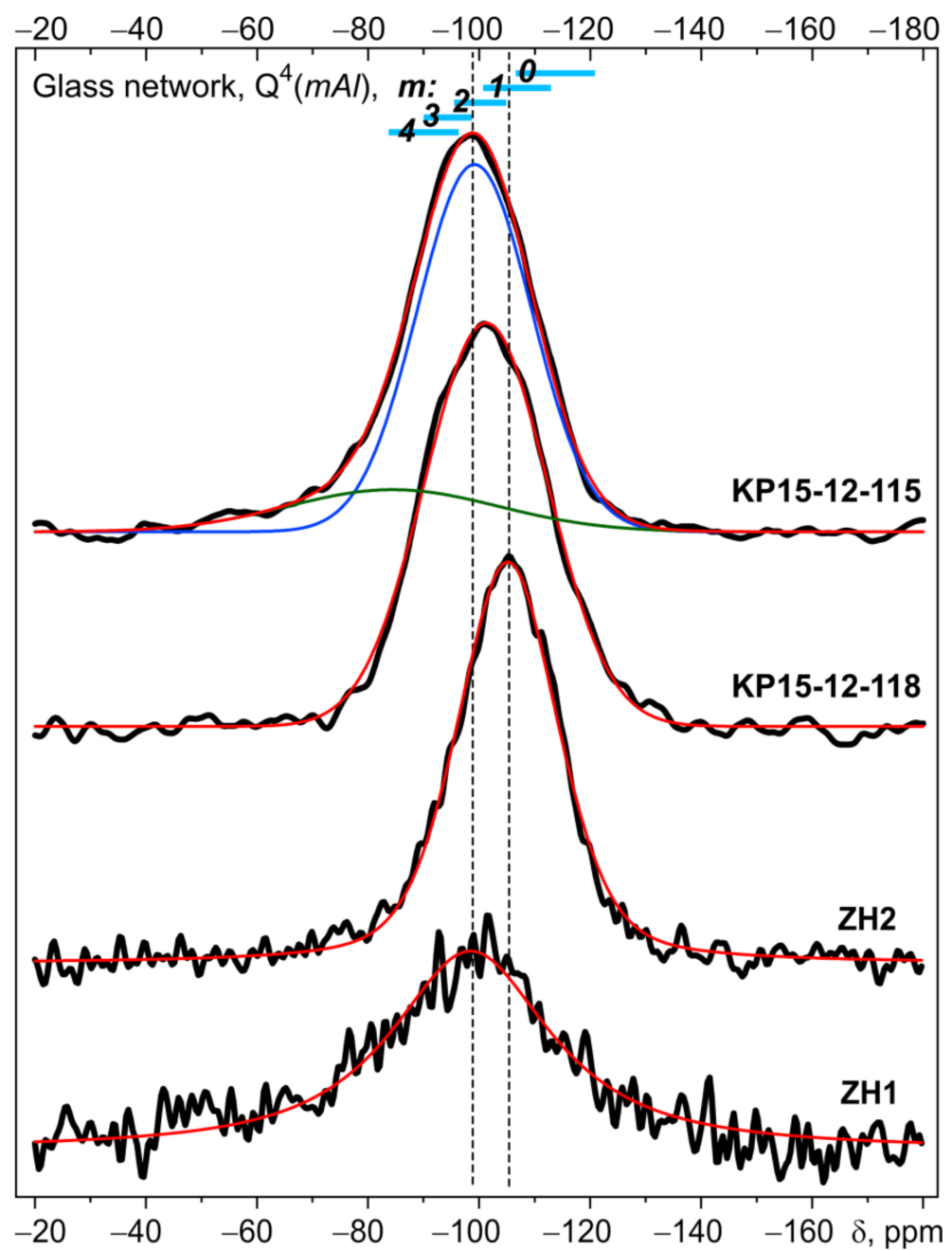

Figure 8. The shape of the isotropic ${ }^{29}$ Si MAS NMR components of the studied glasses. Black lineexperimental, and red lines-fitted spectra. The ranges of chemical shifts of $\mathrm{Q}^{4}(m \mathrm{Al})$ configurations of $\mathrm{SiO}_{4}$-units $[26,49]$ are depicted by the blue bars.

For further analysis, we have used the single-component model implemented in the "CSA MAS" subroutine of the DMFit program [22]. For the fitting we have used Voight contours with variable Lorentz contribution (G/L ratio) (Table 4). The Lorentzian line shape indicates a significant paramagnetic broadening of the NMR signal [27,33]. Such broadening is larger for the ZH1 sample, for which a larger broadening of the ${ }^{27} \mathrm{Al}$ and ${ }^{23} \mathrm{Na}$ NMR lines was also noted. The selected model reproduces well the spectral shapes (Figure 8), but the obtained values of the components of the chemical shift anisotropy tensor are only predictive. A more detailed look at the ${ }^{29} \mathrm{Si}$ NMR spectrum of the KP15-12-115 sample reveals that the central band is slightly asymmetric, indicating the presence of a low-intensity component with the maximum at ca. $-80 \mathrm{ppm}$, which can be attributed either to the $\mathrm{Q}^{2}$ or the $\mathrm{Q}^{4}(4 \mathrm{Al})$ component of pyroxene or plagioclase $[49,50]$. The more symmetric shape of the signal of the KP15-12-118 sample is likely due to the presence of low-intensity components at $-94 \mathrm{ppm},-100 \mathrm{ppm}$, and $-106 \mathrm{ppm}$, which could arise from the traces of plagioclase and quartz in the sample. Note that to the low content of coesite its characteristic ${ }^{29} \mathrm{Si}$ NMR signals at $-108.1 \mathrm{ppm}$ and $-113.9 \mathrm{ppm}$ are not visible, although, previously, coesite have been reliably detected in the Kara UHPHT glasses [13,14]. 
Table 4. The fitted parameters of the ${ }^{29}$ Si MAS NMR of the impact glasses.

\begin{tabular}{ccccc}
\hline Sample & $\delta_{\text {iso }}, \mathbf{p p m}$ & $\boldsymbol{\Delta}_{\text {CS }}, \mathbf{p p m}$ & G/L & A, \% \\
\hline \multirow{2}{*}{ KP15-12-115 } & $-99.1 \pm 0.1$ & $24.2 \pm 0.3$ & 1 & 80 \\
& $-84 \pm 2$ & $44 \pm 2$ & 1 & 20 \\
\hline KP15-12-118 & $-101.2 \pm 0.1$ & $26.1 \pm 0.2$ & 1 & 100 \\
\hline ZH1 & $-99.3 \pm 0.6$ & $35 \pm 3$ & 0.1 & 100 \\
\hline ZH2 & $-105.0 \pm 0.1$ & $24.4 \pm 0.4$ & 0.6 & 100 \\
\hline
\end{tabular}

Note. $\delta_{\text {iso }}$ is the isotropic chemical shift, $\Delta_{\mathrm{CS}}$ is the width (FWHM); G/L is the Gaussian/Lorentzian ratio (1 for Gaussian, 0 for Lorentzian) of the Voigh shape; A is a relative area of the corresponding component.

Thus, mutually consistent analysis of the ${ }^{27} \mathrm{Al},{ }^{23} \mathrm{Na}$, and ${ }^{29} \mathrm{Si} \mathrm{NMR}$ spectra allowed us to identify some of the features of the UHPHT Kara impact glass framework. However, it has to be noted that the presence of finely dispersed pyroxene microcrystals and relict fragments of the target rocks in the Kara glass samples complicate the interpretation of the spectra. Another complicating factor is the relatively high content of paramagnetic iron impurities, localized mainly in the octahedral positions of the glass framework. Interestingly, in the spectra of the Kara glass samples with the higher Fe content than in the zhamanshinites, the effects of paramagnetic broadening were significantly less pronounced, which allowed us to conclude that the Fe atoms are spatially separated in the structure of the Kara glass. We speculate that this is related to the mode of the melt-glass transition: the formation of the Kara vein impact glass probably occurred during slower vitrification of the impact melt and slower cooling of the glass, which led to differentiation of the glass substance with the separation of zones enriched in iron. These iron-saturated fragments do not appear in the NMR spectra due to strong paramagnetic line broadening. In contrast, the melt of the tektites was evidently cooled in the quenching mode, which preserved the homogeneous distribution of paramagnetic impurities.

We interpreted the ${ }^{27} \mathrm{Al}$ MAS NMR spectra of the heterogeneous Kara glass as a superposition of signals from aluminosilicate glass and crystalline impurities of pyroxene and feldspar. The glass of the zhamanshinites is homogeneous, and their ${ }^{27}$ Al MAS NMR spectra consist of only a single strongly paramagnetically broadened signal. In both, the values of the isotropic chemical shift and the quadrupole coupling constant of the glass component of the spectra are typical for the tetrahedral positions ${ }^{\mathrm{IV}} \mathrm{Al}$ atoms of the fully polymerized $\mathrm{Q}^{4}$ aluminosilicate framework, in which all oxygen atoms of the $\mathrm{AlO}_{4}$ tetrahedra are in bridging. According to the ab initio calculations, the values $\delta_{\text {iso }}$ $=61-63$ ppm for glass components of ${ }^{27} \mathrm{Al}$ MAS NMR spectra (Table 2) correspond, on average, to the presence of three $\mathrm{Si}$ and one $\mathrm{Al}$ in the second coordination sphere of the ${ }^{\mathrm{IV}} \mathrm{Al}\left(\mathrm{Q}^{4}(3 \mathrm{Si}, 1 \mathrm{Al})\right.$ configuration) in aluminosilicate glass [43].

Thus, aluminum in the impact glass framework plays the role of network-former, in contrast to iron, which occupies mainly octahedral positions, according to Mössbauer spectroscopy, and refers to network-modifiers of ions. Signals of five coordinated ${ }^{\mathrm{V}} \mathrm{Al}$ $\left(\mathrm{AlO}_{5}\right)$ positions, characteristic of impact glass or high-pressure glass, by present measurements, were not detected, which could probably be explained by possible longer-term of the high-temperature history of condensation of the Kara vein impact glasses, as well as by low spectral resolution due to the strong paramagnetic broadening of NMR signals as is the case for zhamanshinites.

Analysis of the ${ }^{23} \mathrm{Na}$ NMR spectra showed that the bulk of $\mathrm{Na}$ atoms in the Kara glass and the tektites are characterized by similar values of the isotropic chemical shifts and quadrupole coupling constants, typical for aluminosilicate glasses. This indicates the same degree of aluminosity of the glass, which is indeed the case if we take into account that the excess part of the $\mathrm{Al}$ atoms in the Kara glass is localized in the mineral phases. The $\mathrm{Na}$ atoms are located in the highly coordinated positions of the aluminosilicate framework and are the charge compensators of the $\mathrm{Al}^{3+}$ in tetrahedral positions.

Taking into account that only a small fraction of $\mathrm{Fe}^{3+}$ ions is in a tetrahedral position $[14,15]$, one could estimate the nominal degree of glass polymerization in terms of the 
$\mathrm{NBO} / \mathrm{T}$ ratio (non-bridging oxygen, $\mathrm{NBO}$, per tetrahedrally coordinated cation, $\mathrm{T}$ ). The configurations $\mathrm{Q}^{4}, \mathrm{Q}^{3}, \mathrm{Q}^{2}, \mathrm{Q}^{1}$, and $\mathrm{Q}^{0}$ would correspond to $\mathrm{NBO} / \mathrm{T}$ values of $0,1,2,3$ и4, respectively. Calculations of the $\mathrm{NBO} / \mathrm{T}$ values for the studied impact glass, performed on the basis of their compositions (Table 1) according to the procedure described in ([51], p. 118), showed that NBO/T ratios for the Kara glass samples are equal to 0.33 (KP15-12115) and 0.38 (KP15-12-118). For the zhamanshinite, NBO/T values are lower than those of the Kara glasses: 0.2 for ZH1 and 0.1 for ZH2. Nominally, the zhamanshinite glasses are characterized by an even higher degree of polymerization of the $[\mathrm{Si}, \mathrm{Al}] \mathrm{O}_{4}$ framework in almost pure $\mathrm{Q}^{4}$ configuration. Thus, the calculated values of $\mathrm{NBO} / \mathrm{T}$ values are consistent with the hypothesis [16] that the high heterogeneity of the degree of polymerization of $\mathrm{SiO}_{4}$ units in the lattice of the Kara UHPHT impacts glass in comparison with the tektites condensed at atmospheric pressure.

However, calculated NBO/T are slightly overestimated values for Kara glass, since the glass also contains pyroxene with the $\mathrm{Q}^{2}$ type of $\mathrm{SiO}_{4}$ polymerization. Indeed, a higher value NBO/T was obtained for the sample KP15-12-118, which has a higher pyroxene content, according to the NMR data (Table 2). Thus, nominally, the Kara glasses are close to full polymerization in $\mathrm{Q}^{4}$ configuration of $[\mathrm{Si}, \mathrm{Al}] \mathrm{O}_{4}$ groups with a small fraction of $\mathrm{Q}^{3}$ and $\mathrm{Q}^{2}$ configurations. The ${ }^{29} \mathrm{Si}$ NMR spectra of both types of impact glass are mainly described by the superposition of the individual ${ }^{29} \mathrm{Si}$ bands in the $\mathrm{Q}^{4}(m \mathrm{Al})$ configuration. This supports the complete polymerization of the $(\mathrm{Si}, \mathrm{Al}) \mathrm{O}_{4}$ tetrahedral structural units. The most probable configurations are the ones in which 1-2 of the four bridging oxygen atoms belong to the $\mathrm{Si}-\mathrm{O}-\mathrm{Al}$ bonds. The traces of coesite $\left(\mathrm{SiO}_{2}, \mathrm{Q}^{4}\right)$ present in the Kara glass were not detected in the measured ${ }^{29} \mathrm{Si}$ NMR spectra, apparently due to line broadening associated with the microscopic sizes of crystallites and the relatively low content of this high-pressure silica phase in the UHPHT glass. The ${ }^{29} \mathrm{Si}$ NMR spectral signatures of $\mathrm{Q}^{4}$ lines belonging to the structural units $\mathrm{SiO}_{5}$ or $\mathrm{SiO}_{6}$ (stishovite), characteristic of highpressure silica glass, were not detected in the spectra of the studied impact glasses at the analytical conditions used.

\section{Conclusions}

The ${ }^{27} \mathrm{Al},{ }^{23} \mathrm{Na}$, and ${ }^{29} \mathrm{Si}$ MAS NMR spectroscopy showed that the Kara UHPHT vein glasses belong to an amorphous aluminosilicate substance with a high degree of polymerization of the glass framework. Despite the long post-impact period of about 70 million years, and significant hydrothermal alternation of the host rocks, these UHPHT vein formations remained uncrystallized, although they did not retain direct impact markers such as $\mathrm{SiO}_{5}$ and $\mathrm{AlO}_{5}$ units. The primary fine-dispersed pyroxene and coesite precipitates possibly formed during the solidification of the melt and stabilize the glassy state of the surrounding aluminosilicate substance. Furthermore, the unique 70 Ma stability of the Kara UHPHT vein glass may be explained by its high polymerization level, which can limit time-connected glass crystallization and its mineral alteration. In summary, the specific features of NMR spectra of the Kara UHPHT glasses are consistent with the vein hypothesis of their formation under conditions of high-pressures and temperatures resulting in their fluidity, relatively slow solidification with polymerization, and precipitation of mineral phases as the impact melt cools.

Author Contributions: V.L.: Methodology, Formal analysis, Writing—Original Draft preparationReview \& Editing; T.S.: Conceptualization, Writing-Original Draft preparation; A.M. and P.T.: Investigation, Writing-Original Draft preparation. All authors have read and agreed to the published version of the manuscript.

Funding: This research was funded by the Russian Science Foundation, grant number 17-17-01080. 
Acknowledgments: The authors thank Ye. M. Tropnikov for help in SEM studies, M. F. Samotolkova for technical assistance at the paper preparation. The MAS NMR measurements of the impact glass samples were carried out at the Center for Magnetic Resonance (Research Park, St. Petersburg State University, St. Petersburg, Russia). The electron microscopy and spectroscopy investigations of the Kara impactites were provided using facilities of the Center of collective use "GEONAUKA" (IG FRC Komi SC UB RAS, Syktyvkar, Russia).

Conflicts of Interest: The authors declare no conflict of interest. The funders had no role in the design of the study; in the collection, analyses, or interpretation of data; in the writing of the manuscript, or in the decision to publish the results.

\section{References}

1. Tsiok, O.B.; Brazhkin, V.V.; Lyapin, A.G.; Khvostantsev, L.G. Logarithmic Kinetics of the Amorphous-Amorphous Transformations in $\mathrm{SiO}_{2}$ and $\mathrm{GeO}_{2}$ Glasses under High Pressure. Phys. Rev. Lett. 1998, 80, 999-1002. [CrossRef]

2. Brazhkin, V.V.; Katayama, Y.; Trachenko, K.; Tsiok, O.B.; Lyapin, A.G.; Artacho, E.; Dove, M.; Ferlat, G.; Inamura, Y.; Saitoh, H. Nature of Structural Transformations in the $\mathrm{B}_{2} \mathrm{O}_{3}$ Glass under High Pressure. Phys. Rev. Lett. 2008, 101, 35702. [CrossRef] [PubMed]

3. Benmore, C.J.; Soignard, E.; Amin, S.A.; Guthrie, M.; Shastri, S.D.; Lee, P.L.; Yarger, J.L. Structural and topological changes in silica glass at pressure. Phys. Rev. 2010, 81, 54105. [CrossRef]

4. Pronin, A.A.; Kondrin, M.V.; Lyapin, A.G.; Brazhkin, V.V.; Volkov, A.A.; Lunkenheimer, P.; Loid, A. Glassy dynamics under superhigh pressure. Phys. Rev. 2010, 81, 41503. [CrossRef] [PubMed]

5. Sato, T.; Funamori, N. High-pressure structural transformation of $\mathrm{SiO}_{2}$ glass up to $100 \mathrm{GPa}$. Phys. Rev. 2010, 82, 184102. [CrossRef]

6. Brazhkin, V.V.; Fomin, Y.u.D.; Lyapin, A.G.; Ryzhov, V.N.; Trachenko, K. Two Liquid States of Matter: A Dynamical Line on a Phase Diagram. Phys. Rev. 2012, 85, 31203. [CrossRef]

7. Deschamps, T.; Margueritat, J.; Martinet, C.; Mermet, A.; Champagnon, B. Elastic Moduli of Permanently Densified Silica Glasses. Sci. Rep. 2014, 4, 7193. [CrossRef]

8. Kono, Y.; Kenney-Bensona, C.; Ikutaa, D.; Shibazaki Yu Wang, Y.; Shena, G. Ultrahigh-pressure polyamorphism in GeO 2 glass with coordination number $>6$. PNAS 2016, 113, 3436-3441. [CrossRef]

9. Bolmatov, D.; Brazhkin Trachenko, V.V. Thermodynamic behavior of supercritical matter. Nat. Commun. 2013, 4, 2331. [CrossRef]

10. Borisova, P.A.; Blanter, M.S.; Brazhkin, V.V.; Somenkov, V.A.; Filonenko, V.P. Phase transformations in amorphous fullerite $\mathrm{C}_{60}$ under high pressure and high temperature. J. Phys. Chem. Solids. 2015, 83, 104-108. [CrossRef]

11. Shultz, M.M.; Mazurin, O.V. Contemporary Concept of Glass Structure and Their Properties; Nauka: Leningrad, Russia, 1998. (In Russian)

12. Guerette, M.; Ackerson, M.R.; Thomas, J.; Yuan, F.; Watson, E.B.; Walker, D.; Huang, L. Structure and Properties of Silica Glass Densified in Cold Compression and Hot Compression. Sci. Rep. 2015, 5, 15343. [CrossRef] [PubMed]

13. Shumilova, T.G.; Zubov, A.A.; Isaenko, S.I.; Karateev, I.A.; Vasiliev, A.I. Mysterious long-living ultrahigh pressure or secondary impact crisis. Sci. Rep. 2020, 10, 2591. [CrossRef]

14. Shumilova, T.G.; Lutoev, V.P.; Isaenko, S.I.; Kovalchuk, N.S.; Makeev, B.A.; Lysiuk AYu Zubov, A.A.; Ernstson, K. Spectroscopic features of ultrahigh-pressure impact glasses of the Kara astrobleme. Sci. Rep. 2018, 8, 6923. [CrossRef]

15. Lutoev, V.P.; Potapov, S.S.; Lysuyk AYu Golovataya, O.S. Features of natural and synthetic silica glasses by FTIR, EPS and Mössbouer spectroscopy. In Mineralogy of Technogenesis-2018; Potapov, S.S., Anfilogov, V.N., Popov, V.A., Eds.; Institute of Mineralogy UB RAS: Miass, Russia, 2018; pp. 26-51. (In Russian)

16. Golubev, Y.A.; Shumilova, T.G.; Isaenko, S.I.; Radaev, V.A.; Utkin, A.A.; Makeev, B.A.; Ernstson, K. Microscopic studies of ultra-high pressure glasses from impactites of the Kara astrobleme. J. Non-Cryst. Solids 2020, 534, 119951. [CrossRef]

17. Koroleva, O.N.; Anfilogov, V.N.; Shatskiy, A.; Litasov, K.D. Structure of $\mathrm{Na}_{2} \mathrm{O}-\mathrm{SiO}_{2}$ melt as a function of composition: In situ Raman spectroscopic study. J. Non-Cryst. Solids 2013, 375, 62-68. [CrossRef]

18. Angeli, F.; Gaillard, M.; Jollivet, P.; Charpentier, T. Influence of glass composition and alteration solution on leached silicate glass structure: A solid-state NMR investigation. Geochim. Cosmochim. Acta 2006, 70, 2577-2590. [CrossRef]

19. Florenskiy, P.V. The Zhamanshin meteorite crater (Northern Aral Sea region) and its tektites and impactites. Int. Geol. Rev. 1997, 19, 526-538. [CrossRef]

20. Kartashov, P.M.; Gornostaeva, T.A.; Mokhov, A.V.; Bogatikov, O.A. The Natural High Pressure Phase of Cubic CdSe in Impact Glass from Zhamanshin Crater. Dokl. Earth Sci. 2016, 467, 412-414. [CrossRef]

21. Gornostaeva, T.A.; Mokhov, A.V.; Kartashov, P.M.; Bogatikov, O.A. Condensate glasses from the Zhamanshin Crater. I. Irghizites. Petrology 2016, 24, 1-20. [CrossRef]

22. Massiot, D.; Fayon, F.; Capron, M.; King, I.; Le Calvé, S.; Alonso, B.; Durand, J.-O.; Bujoli, B.; Gan, Z.; Hoatson, G. Modelling oneand two-dimensional Solid State NMR spectra. Magn. Reson. Chem. 2002, 40, 70-76. [CrossRef]

23. Makeyev, A.B.; Lutoev, V.P.; Vtorov, I.P.; Braynchaninova, N.I.; Makavetskas, A.R. Composition and spectroscopy of olivine xenocrysts from the Hawaiian tholeiitic basalts. Uchenye Zap. Kazan. Univ. Seriya Estestv. Nauk. 2020, 162, 253-273. [CrossRef] 
24. Phillips, B.L.; Kirkpatrick, R.J.; Hovis, G.L. ${ }^{27}$ A1, ${ }^{29} \mathrm{Si}$, and ${ }^{23}$ Na MAS NMR Study of an Al, Si Ordered Alkali Feldspar Solid Solution Series. Phys. Chem. Miner. 1988, 16, 262-275. [CrossRef]

25. Kohn, S.C.; Dupree, R.; Mortuza, M.G. The interaction between water and aluminosilicate magmas. Chem. Geol. 1992, 96, 399-409. [CrossRef]

26. Brus, J.; Abbrent, S.; Kobera, L.; Urbanova, M.; Cuba, P. Advances in ${ }^{27} \mathrm{Al}$ MAS NMR Studies of Geopolymers. Annu. Rep. NMR Spectrosc. 2016, 88, 79-147. [CrossRef]

27. Kelsey, K.E.; Stebbins, J.F.; Singer, D.N.; Brown, G.E.; Mosenfelder, J.L.; Asimow, P.D. Cation field strength effects on high pressure aluminosilicate glass structure: Multinuclear NMR and La XAFS results. Geochim. Cosmochim. Acta 2009, 73, 3914-3933. [CrossRef]

28. Kelsey, K.E.; Stebbins, J.F.; Mosenfelder, J.L.; Asimow, P.D. Simultaneous aluminum, silicon, and sodium coordination changes in 6 GPa sodium aluminosilicate glasses. Am. Mineral. 2009, 94, 1205-1215. [CrossRef]

29. Bista, S.; Stebbins, J.F.; Hankins, W.B.; Sisson, T.W. Aluminosilicate melts and glasses at 1 to 3 GPa: Temperature and pressure effects on recovered structural and density changes. Am. Mineral. 2015, 100, 2298-2307. [CrossRef]

30. Schmidt, B.C.; Riemer, T.; Kohn, S.C.; Behrens, H.; Dupree, R. Different water solubility mechanisms in hydrous glasses along the Qz-Ab Join: Evidence from NMR Spectroscopy. Geochim. Cosmochim. Acta 2000, 64, 513-526. [CrossRef]

31. Haouas, M.; Taulella, F.; Martineau, C. Recent advances in application of ${ }^{27} \mathrm{Al}$ NMR spectroscopy materials science. Prog. Nucl. Magn. Reson. Spectrosc. 2016, 94-95, 11-36. [CrossRef]

32. Youngman, R. NMR Spectroscopy in Glass Science: A Review of the Elements. Materials 2018, 11, 476. [CrossRef]

33. Schroeder, P.A.; Pruett, R.J. Fe ordering in kaolinite: Insights ${ }^{29} \mathrm{Si}$ and ${ }^{27} \mathrm{Al}$ MAS NMR spectroscopy. Am. Mineral. 1996, 81, 26-38. [CrossRef]

34. D'Espinose de Lacaillerie, J.-B.; Fretigny, C.; Massiot, D. MAS NMR spectra of quadrupolar nuclei in disordered solids: The Czjzek model. J. Magn. Reson. 2008, 192, 244-251. [CrossRef]

35. Neuville, D.R.; Cormier, L.; Massiot, D. Al environment in tectosilicate and peraluminous glasses: A ${ }^{27}$ Al MQ-MAS NMR, Raman, and XANES investigation. Geochim. Cosmochim. Acta 2004, 68, 5071-5079. [CrossRef]

36. Pronin, A.A.; Kondrin, M.V.; Lyapin, A.G.; Brazhkin, V.V.; Volkov, A.A.; Lunkenheimer, P.; Samoson, A. Satellite transition high-resolution NMR of quadrupolar nuclei in powders. Chem. Phys. Lett. 1985, 119, 29-32. [CrossRef]

37. Lippma, E.; Samoson, A.; Magi, M. High-Resolution ${ }^{27}$ Al NMR of Aluminosilicates. J. Am. Chem. Soc. 1986, 108, 1730-1735. [CrossRef]

38. Diallo, B.; Allix, M.; Veron, E.; Sarou-Kanian, V.; Bardez-Giboire, I.; Montouillout, V.; Pellerin, N. Deconvolution method of ${ }^{29}$ Si MAS MNR spectra applied to homogeneous and phase separated lanthanum aluminosilicate glasses. J. Non-Cryst. Solids 2019, 503-504, 352-365. [CrossRef]

39. Flemming, R.L.; Terskikh, V.; Ye, E. Aluminum environments in synthetic Ca-Tschermak clinopyroxene $\left(\mathrm{CaAlAlSiO}_{6}\right)$ from Rietveld refinement, ${ }^{27} \mathrm{Al} \mathrm{NMR}$, and first-principles calculations. Am. Mineral. 2015, 100, 2219-2230. [CrossRef]

40. Kohn, S.C.; Roome, B.M.; Smith, M.E.; Howes, A.P. Testing a potential mantle geohygrometer; the effect of dissolved water on the intracrystalline partitioning of $\mathrm{Al}$ in orthopyroxene. Earth Planet. Sci. Lett. 2005, 238, 342-350. [CrossRef]

41. Begaudeau, K.; Morizet, Y.; Florian, P.; Paris, M.; Mercier, J.-C. Solid-state NMR analysis of Fe-bearing minerals: Implications and applications for Earth sciences. Eur. J. Mineral. 2012, 24, 535-550. [CrossRef]

42. Palke, A.C.; Stebbins, J.F.; Frost, D.J.; McCammon, C.A. Incorporation of Fe and $\mathrm{Al}$ in $\mathrm{MgSiO}_{3}$ perovskite: An investigation by ${ }^{27} \mathrm{Al}$ and ${ }^{29} \mathrm{Si}$ NMR spectroscopy. Am. Mineral. 2012, 97, 1955-1964. [CrossRef]

43. Pedone, A.; Gambuzzi, E.; Malavasi, G.; Menziani, M.C. First-principle simulation of the ${ }^{27} \mathrm{Al}$ and ${ }^{17} \mathrm{O}$ solid-state NMR spectra of the $\mathrm{CaAl}_{2} \mathrm{Si}_{3} \mathrm{O}_{19}$ glass. Theor. Chem. Acc. 2012, 131, 1147. [CrossRef]

44. Massiot, D.; Bessada, C.; Coutures, J.P.; Taulelle, F.A. Quantitative Study of ${ }^{27}$ Al MAS NMR in Crystalline YAG. J. Magn. Reson. 1990, 90, 231-242. [CrossRef]

45. Lee, S.K.; Stebbins, J.F. The distribution of sodium ions in aluminosilicate glasses: A high-field Na-23 MAS and 3Q MAS NMR study. Geochim. Cosmochim. Acta 2003, 67, 1699-1709. [CrossRef]

46. Gambuzzi, E.; Charpentier, T.; Menziani, M.C.; Pedone, A. Computational interpretation of ${ }^{23}$ Na MQMAS NMR spectra: A comprehensive investigation of the Na environment in silicate glasses. Chem. Phys. Lett. 2014, 612, 56-61. [CrossRef]

47. Maekawa, H.; Nakao, T.; Shimokawa, S. Coordination of sodium ions in $\mathrm{NaAlO}_{2}-\mathrm{SiO}_{2} \mathrm{melts}$ at high temperature. Phys. Chem. Miner. 1997, 24, 53-65. [CrossRef]

48. Fiske, P.S.; Nellis, W.J.; Xu Zhi Stebbins, J.F. Shocked quartz: A ${ }^{29}$ Si magic-angle-spinning nuclear magnetic resonance study. Am. Mineral. 1998, 83, 1285-1292. [CrossRef]

49. Kirkpatrick, R.J.; Smith, K.A.; Schramm, S.; Turner, G.; Yang, W.-H. Solid-state nuclear magnetic resonance spectroscopy of minerals. Ann. Rev. Earth Planet. Sci. 1985, 13, 29-47. [CrossRef]

50. Kirkpatrick, R.J.; Carpenter, M.A.; Yang, W.-H.; Montez, B. ${ }^{29}$ Si magic-angle NMR spectroscopy of low-temperature ordered plagioclase feldspar. Nature 1987, 325, 236-238. [CrossRef]

51. Mysen, B.; Richet, P. Silicate Glasses and Melts, 2nd ed.; Elsevier Science: Amsterdam, The Netherlands, 2019; p. 118. [CrossRef] 